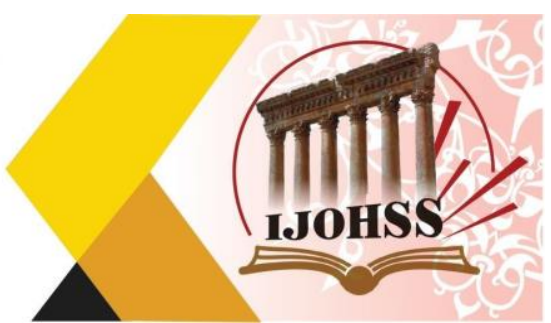

\title{
المفاضلة بين البرامج الارشادية من وجهة نظر المرشدين التربويين
}

\author{
د. نضال نجيب عارف أحمد العزاوي \\ تدريسية في معهد الفنون الجميلة للبنات/ صباحي الفي الفي

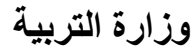 \\ العراق التربية \\ alazawinedhal@yahoo.com
}

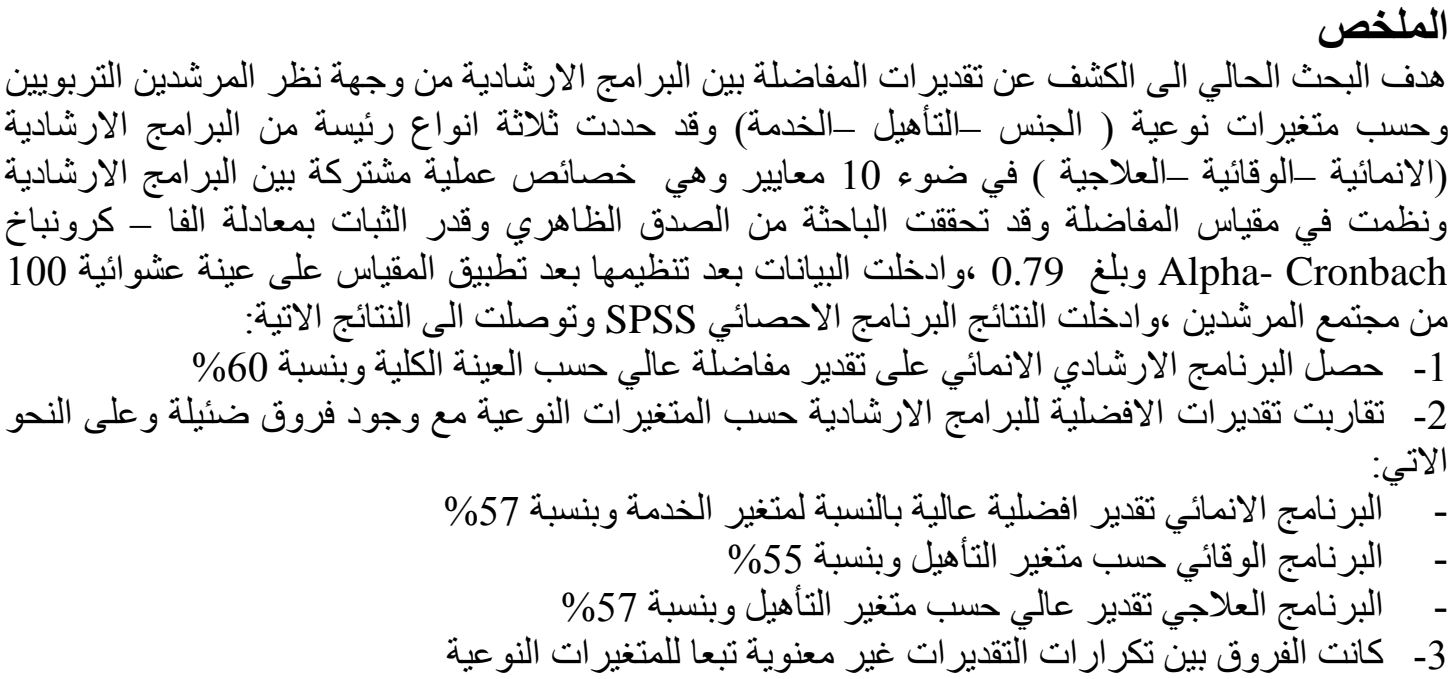

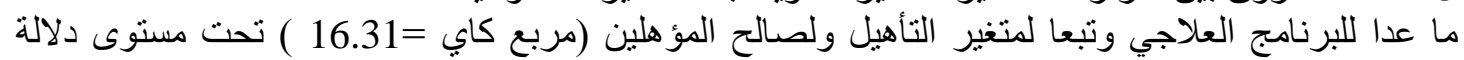

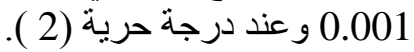

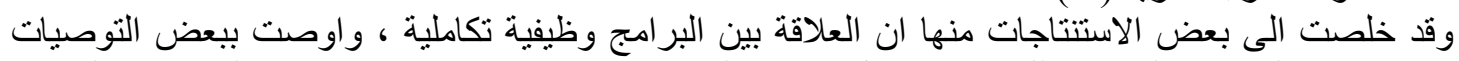

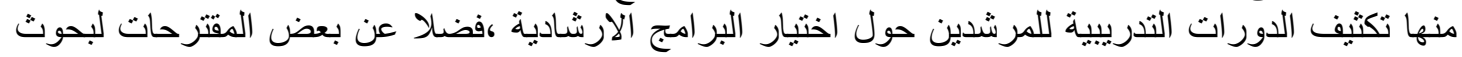
تطويرية وتكميلية . 


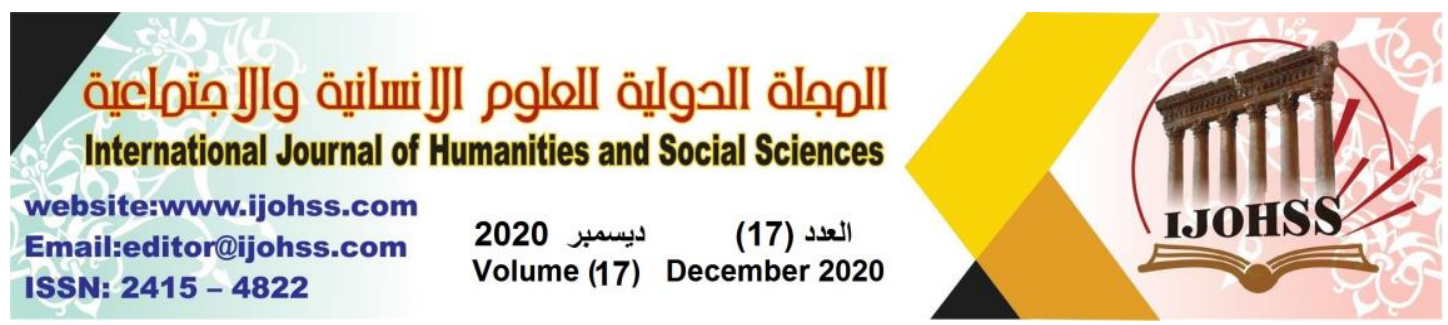

\title{
Differentiation between Counseling programs from the viewpoint of educational counselors
}

\author{
Dr. Nidal Najeeb Aref Ahmed Al-Azzawi \\ Teaching at the Institute of \\ Fine Arts for Girls / Morning \\ Ministry of Education - Iraq \\ alazawinedhal@yahoo.com
}

\begin{abstract}
The aim of the current research is to uncover estimates of the comparison between extension programs from the point of view of educational counselors and volunteers of the types of programs (gender - rehabilitation - the three). The types of extension programs (developmental - preventive - treatment) have been identified in light of 10 characteristics of common practical characteristics between counsel ring programs. And it was organized in the comparison scale, and the researcher verified the apparent validity and the reliability of the Alpha-Cronbach equation, 0.79 , and entered after the data after applying the scale on a random sample of 100 of the mentors' community, and the results entered the statistical program SPSS :

1- The development advisory program obtained a high preference rating according to the total sample, at a rate of $60 \%$

2- The preference estimates for the extension programs are converged according to the qualitative variables, with minimal differences, as follows:

- Development Program appreciation of a high preference for the service variable, at $57 \%$ - Preventive program according to the qualification variable, at a rate of 55\%The treatment program is highly rated according to the qualification variable, at $57 \%$ 3- The differences between the frequencies of the estimates were not significant according to the qualitative variables Except for the treatment program and according to the qualification variable and for the benefit of the qualified (chi-square $=16.31$ ) under the significance level 0.001 and at the degree of freedom (2).

It concluded with some conclusions, including that the relationship between the programs is functional and complementary and recommended some recommendations, including intensifying training courses for mentors on choosing extension programs, as well as some proposals for development and complementary research.
\end{abstract}

Keywords: differentiation, indicative programs, differentiation criteria. 


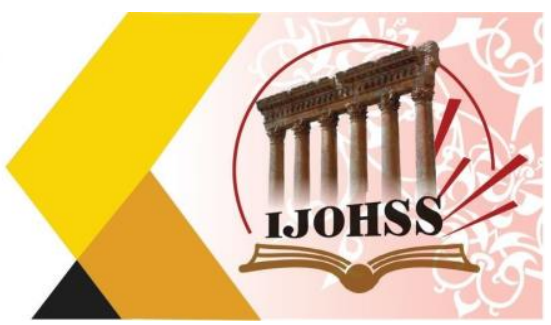

\section{الفصل الاول : التعريف بالبحث}

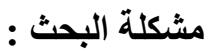

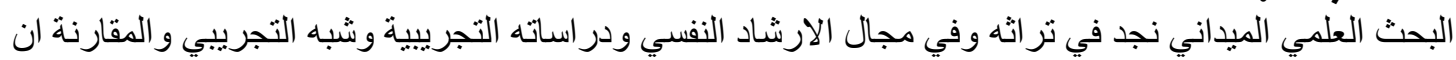

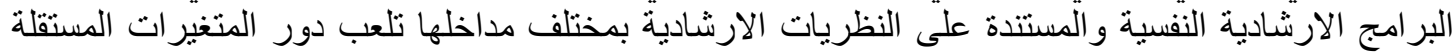

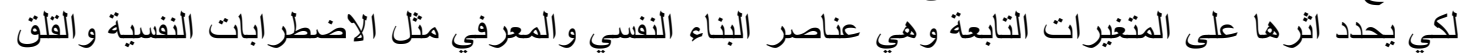

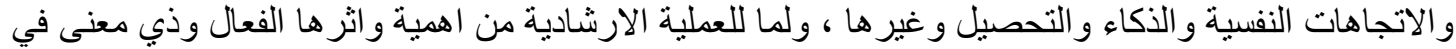

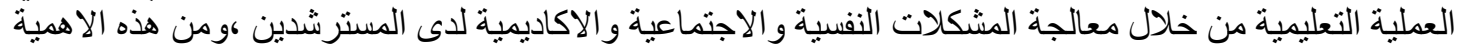

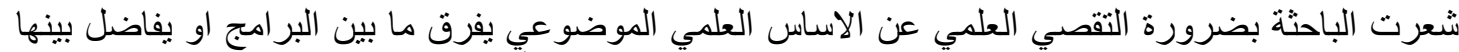

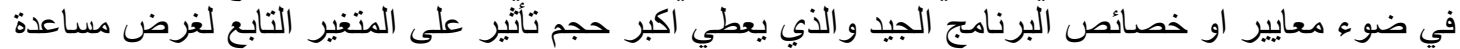

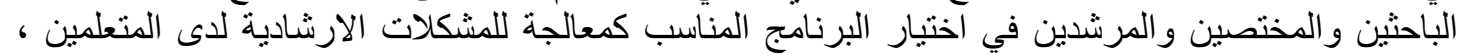

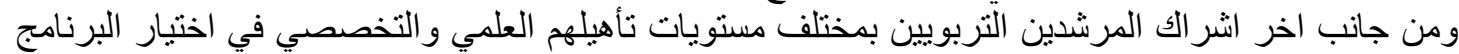

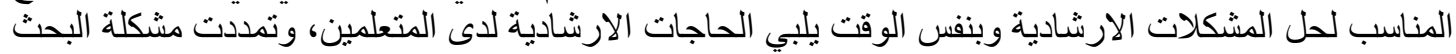

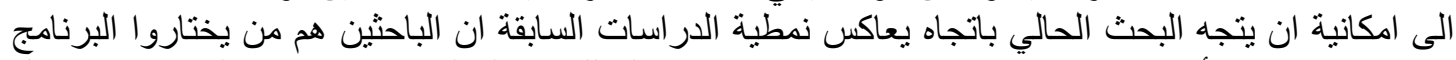

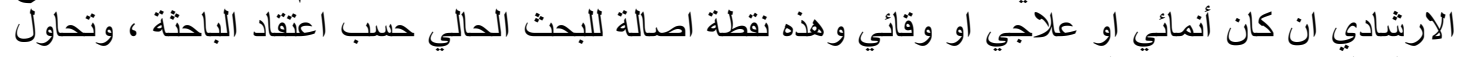
مشكلة البحث الاجابة عن التساؤلات الاتئية الاتية:

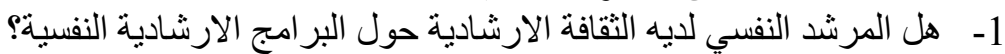

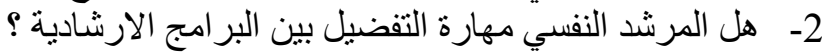

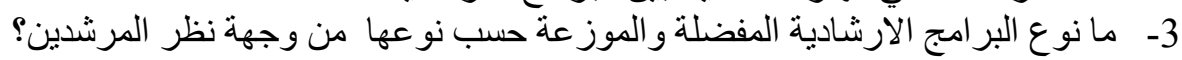

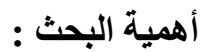
بعد الحرب العالمية الثانية أنتبه المعنيون في الدول الصناعية إلى أهمية تقديم الخدمات الإرشادية في المدارس

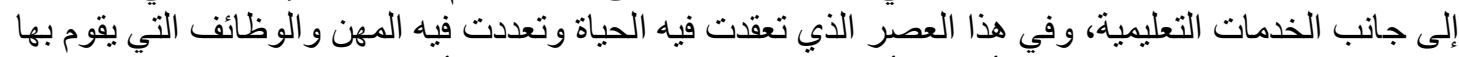

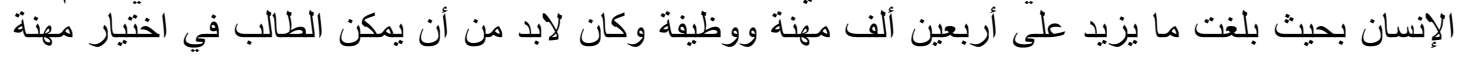

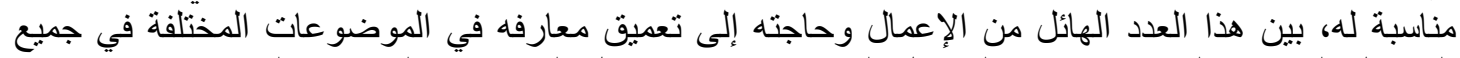

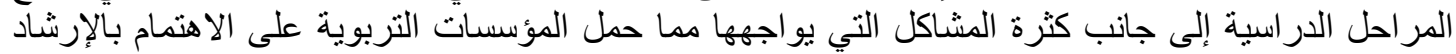

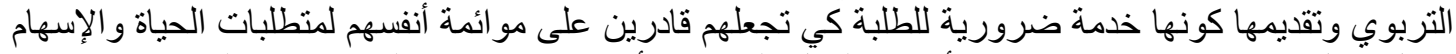

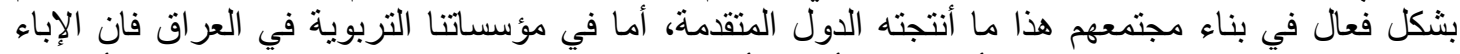

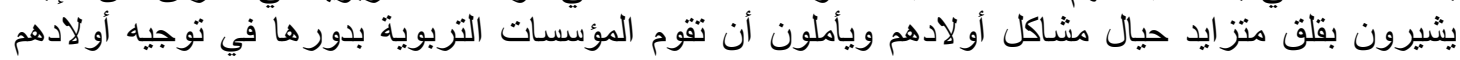

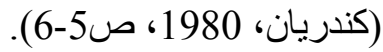

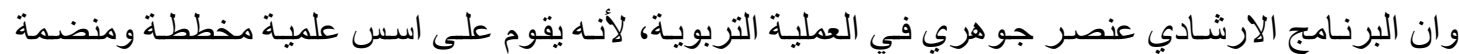

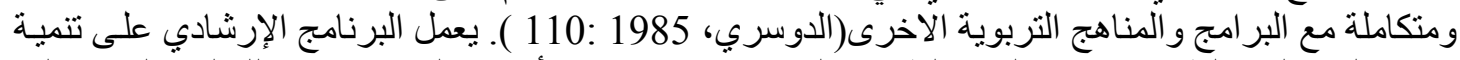

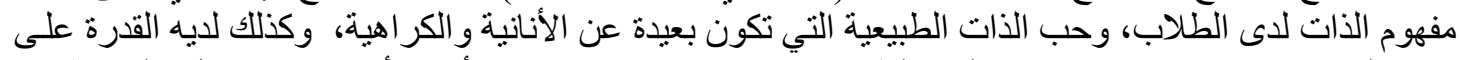

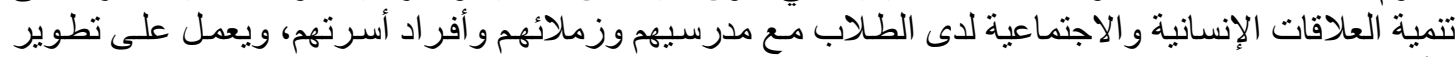

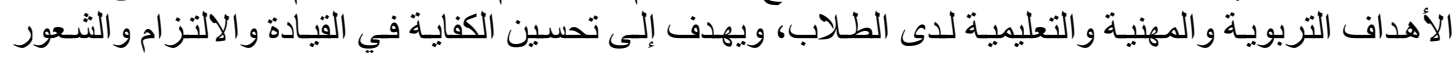

بالمسؤولية و المو اظبة على الدوام (Higgins, 1983, 37).

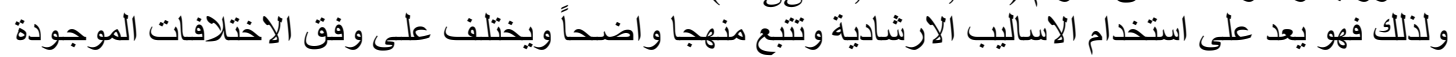

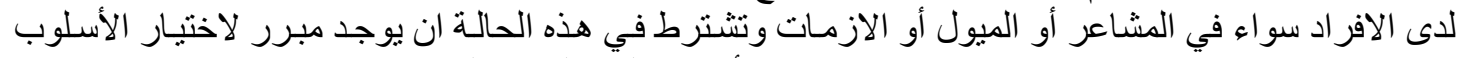

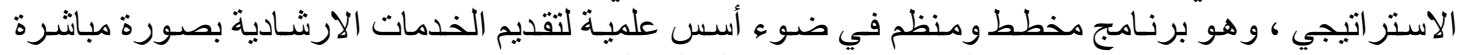

(ملحم، (165: 2008$)$

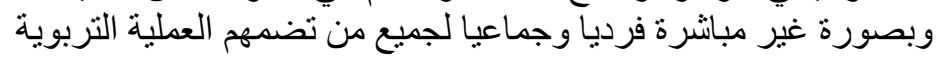




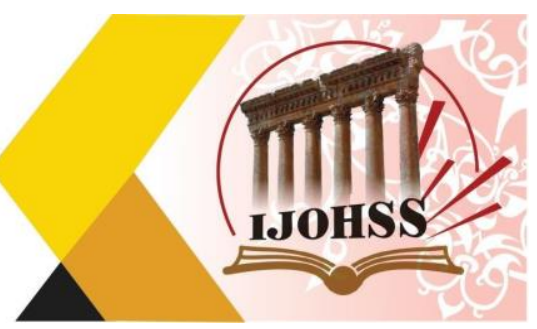

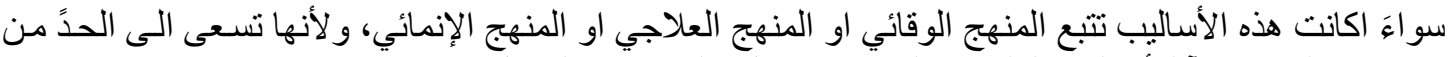

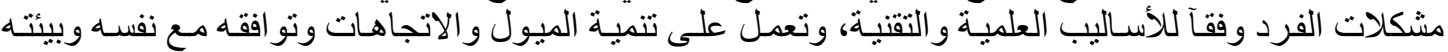

(Berdie, 1959: 157-176)

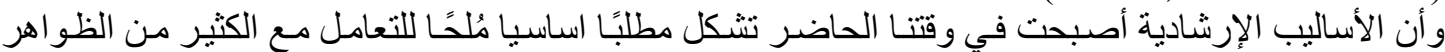

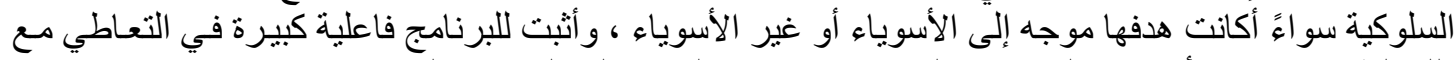

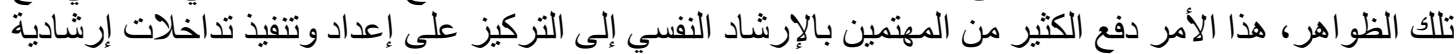

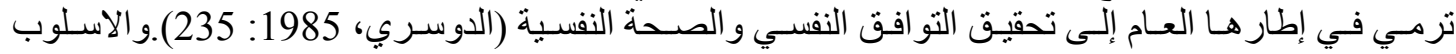

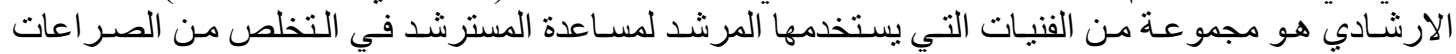

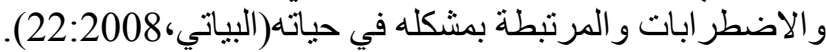

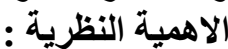

ان تحقيق الاهداف التعليمية العامة بمختلف مجالاتها ينوقف على شئل شئ التفاعل بين عناصر العملية التعليمية

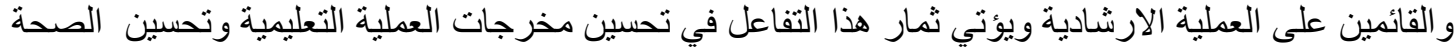

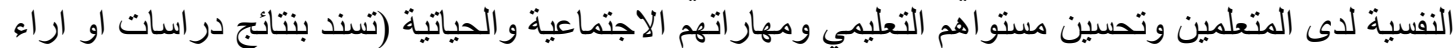

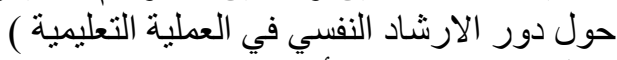
تكمل كتابة الاهمية بالأفكار ألاتية :

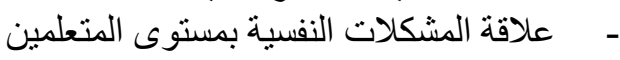

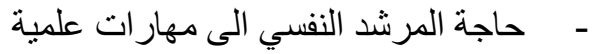

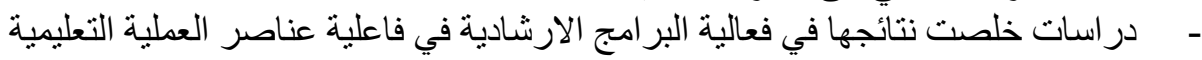
الاهداف : 1- الكثف عن البر امج الارشادية المفضلة من وجهة نظر المرشدين النفسيين وقد اشتقت الباحثة الفرضية الصفرية الاتية:

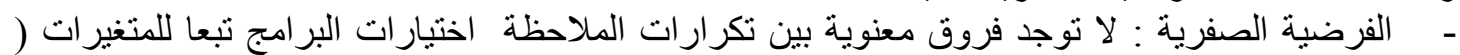

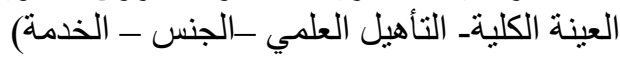

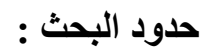
يتحدد البحث البحالي باختيار عينة عشو ائية من المرشدين التربويين في مدينة بغداد ضمن العام الدراسي 2020- 2021

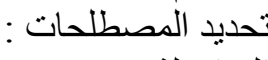

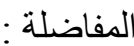
البرنامج الإرشادي(Counseling Program ) عرفه كل من : 1 بأنه برنامج تم التخطُيط لله وفق أسس علمية ويتكون من مجمو عة خدمات إرشـادية مباشـرة و غير مباشـرة ويتم

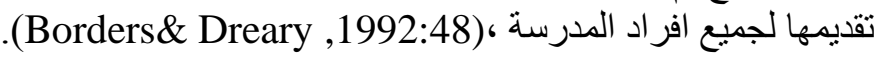
2.

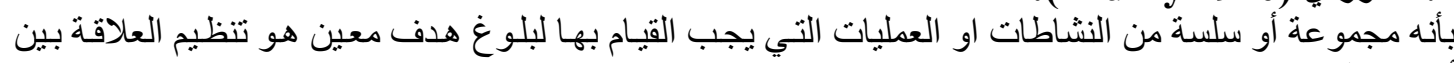

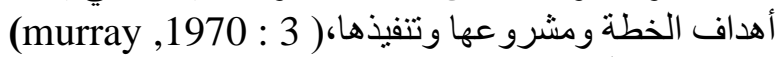
3.

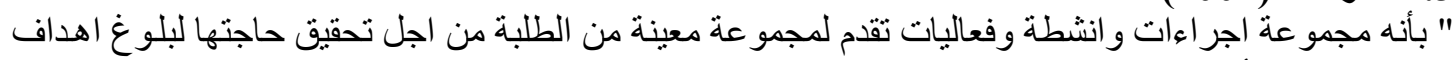

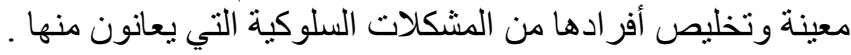

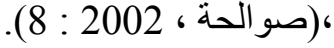




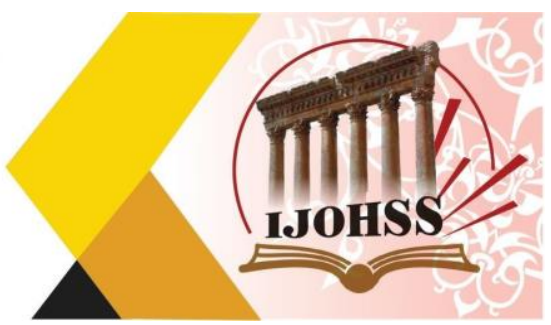

\section{الفصل الثاني : الاطار النظري ودراسات سابقة}

مفهوم الإرشاد:.

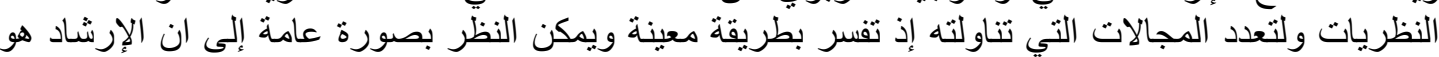

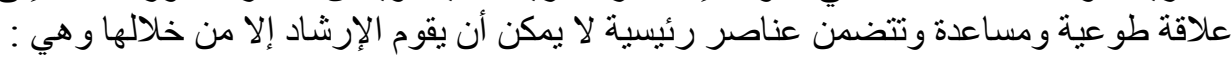

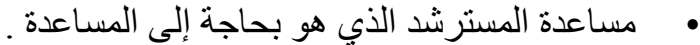

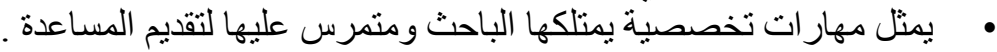

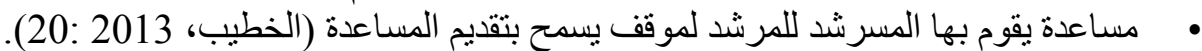

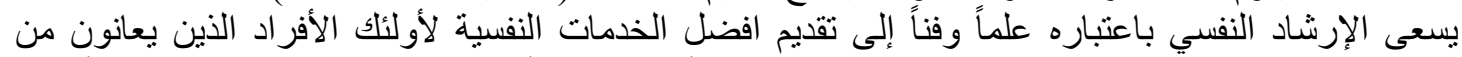

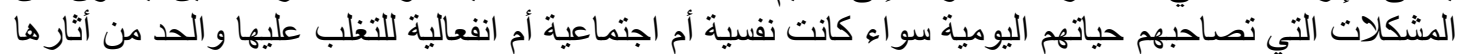

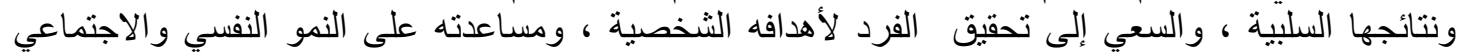

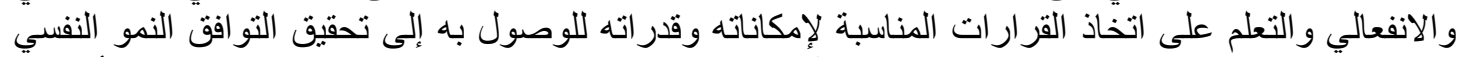

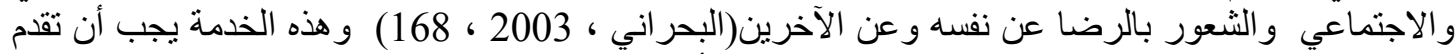

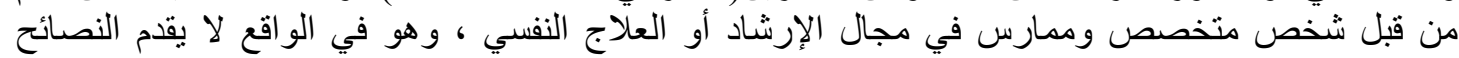

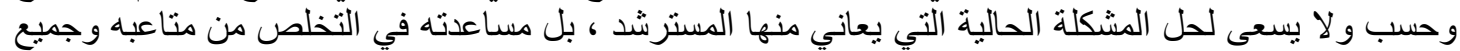

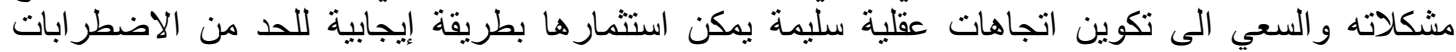

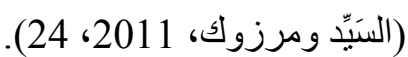
الانفعالية التي تؤثر على تفكيره وسلوكه غير النوات السوي

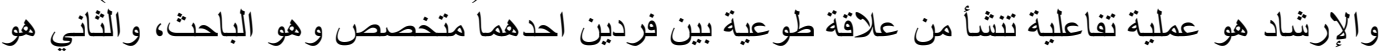

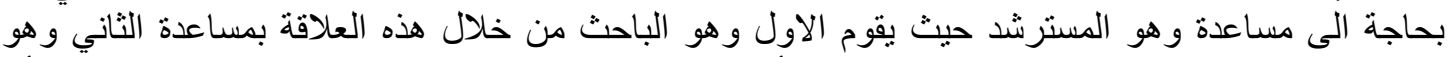

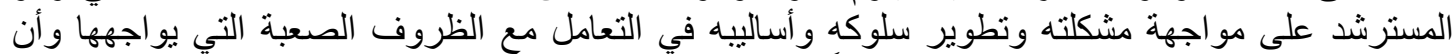

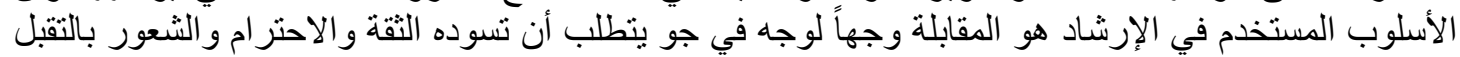

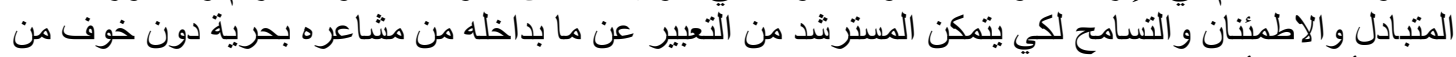

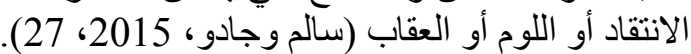

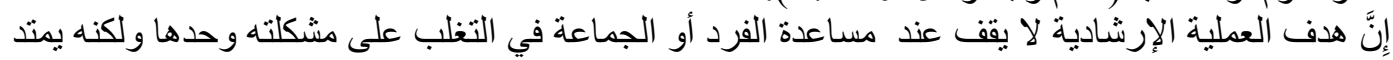

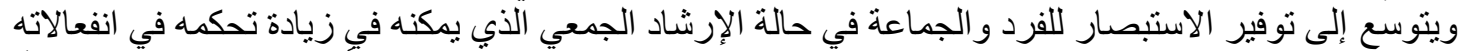

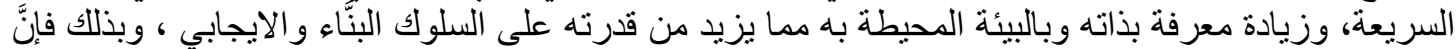

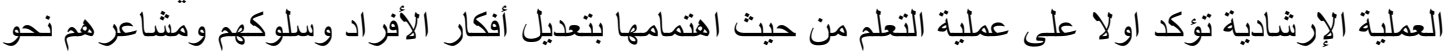

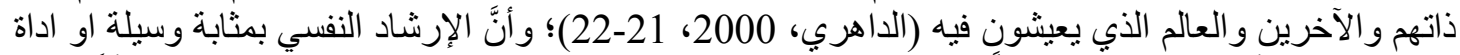

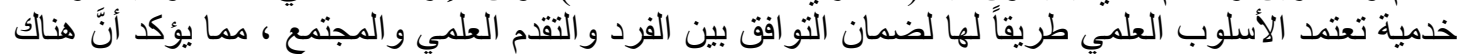

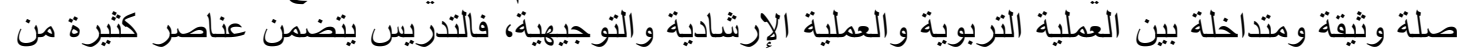

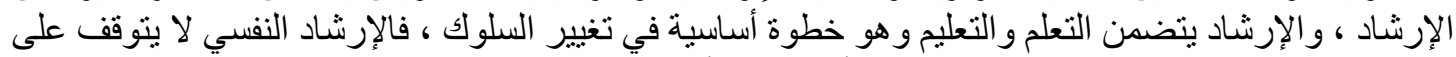

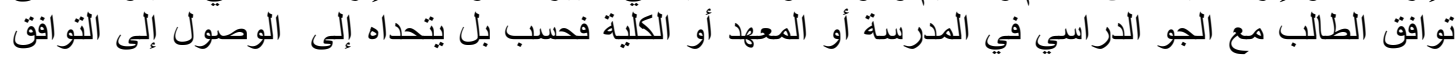

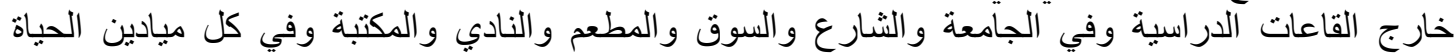

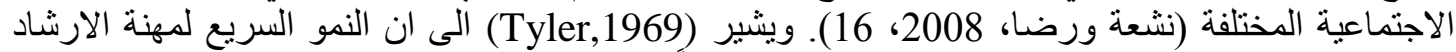

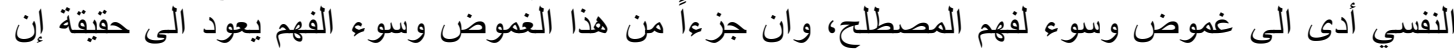

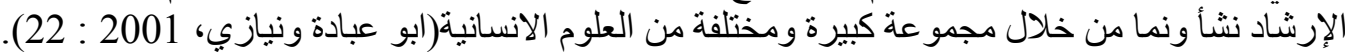

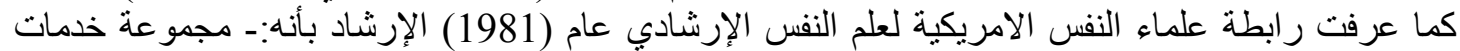

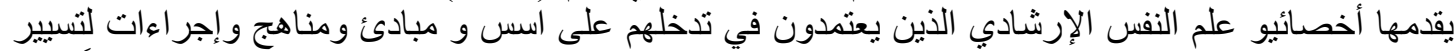

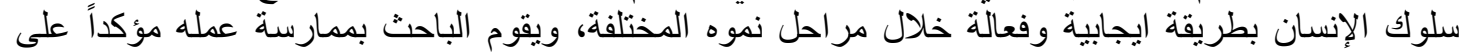

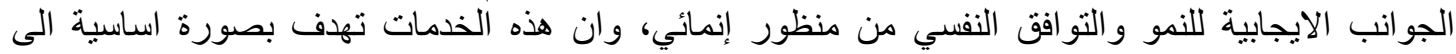

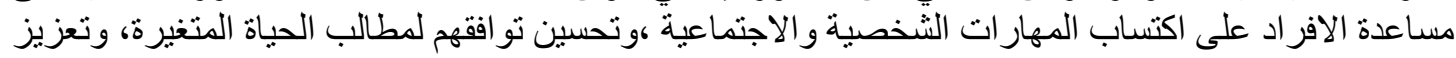




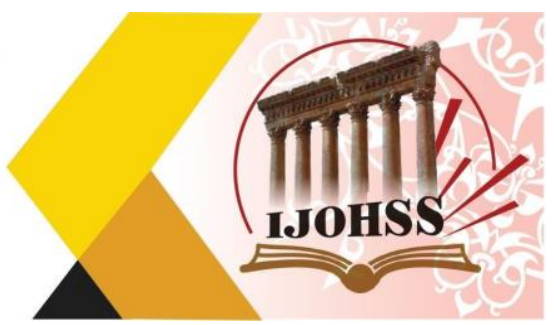

مهار اتهم للتعامل مع البيئة التي تحيطهم، و اكتسابهم المهارات و القدرة على حل المشكلات و اتخاذ القرارات(ابو

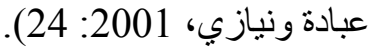

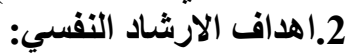

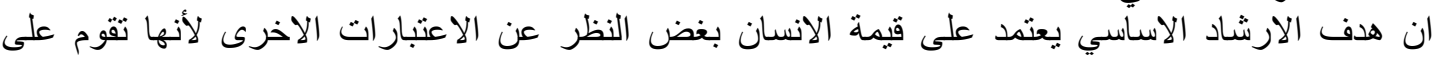

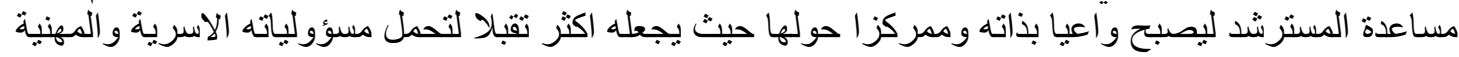

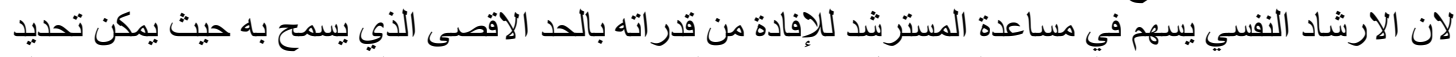

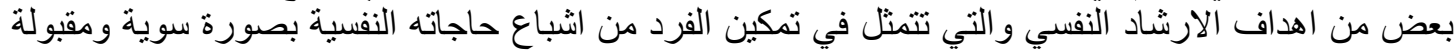

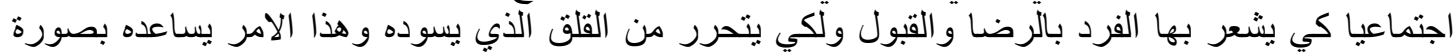

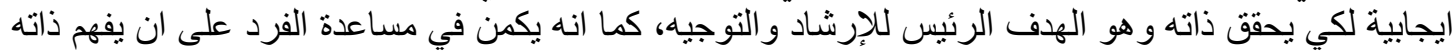

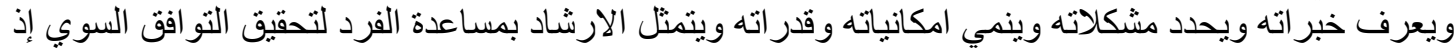

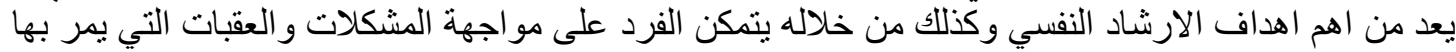

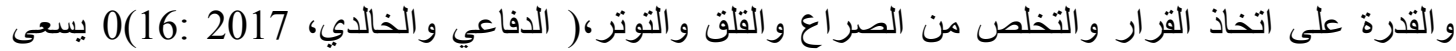

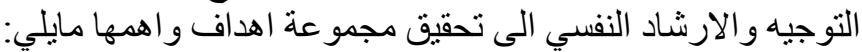

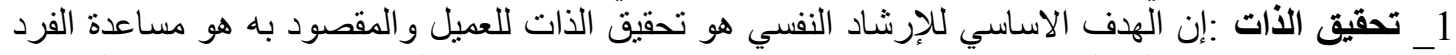

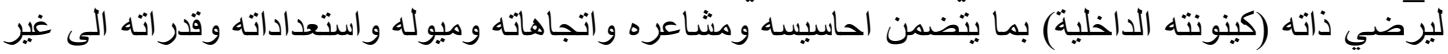

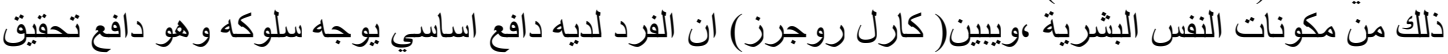

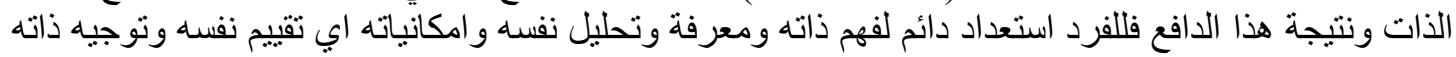

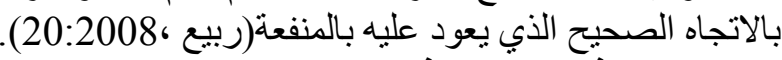
2. تحقيق توافق الفرد مع ذاته وبيئته:

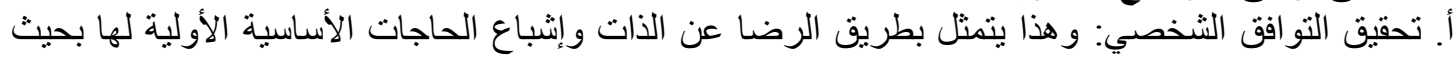

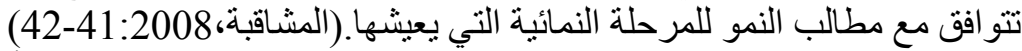
ب. تحقيق التو افق التربوي: مساعدة الطلبة (المسترشدين )على التحصيل الأكاديمي وفق قدراتهم وميولهم في

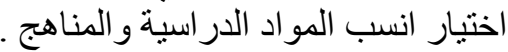

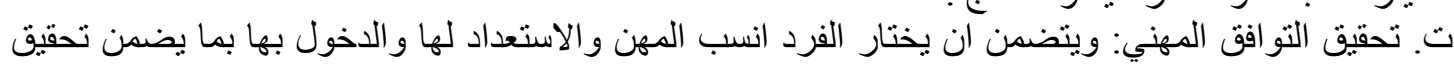

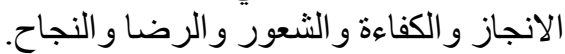

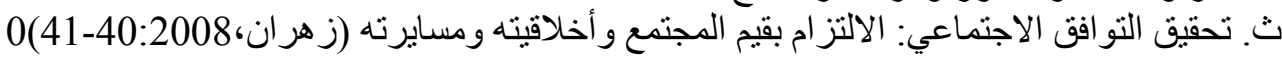

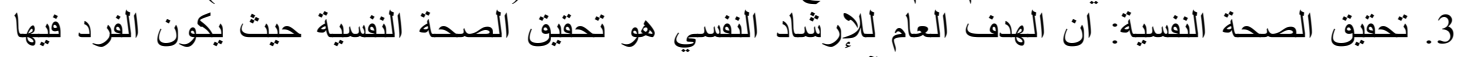

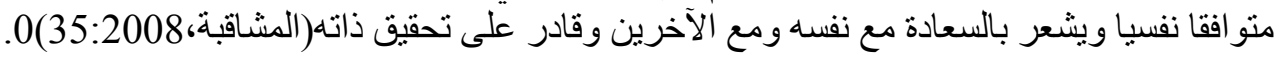

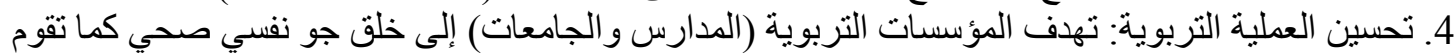
على احترام الطالب كفرد و عضو في الجماعة وتوفير فئر مناخ من الحرية والأمن النفسي لتنمية الثخصية المتكاملة

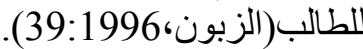

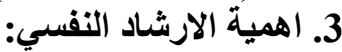

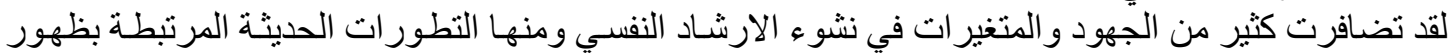

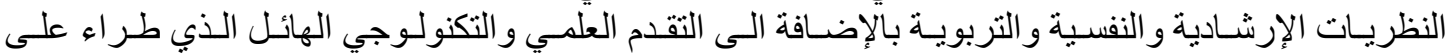

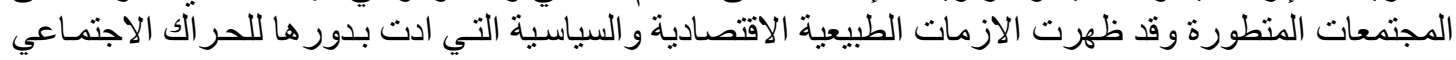

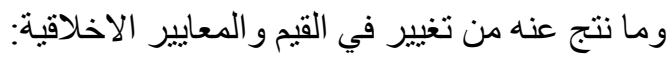

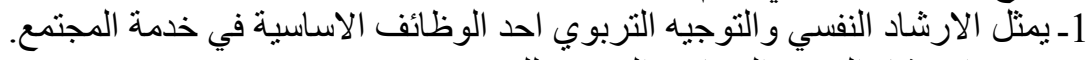

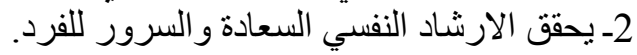

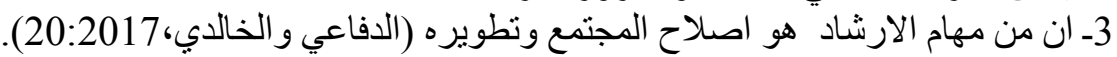

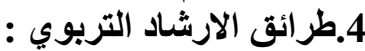

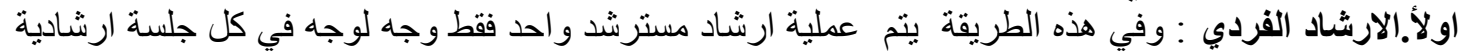

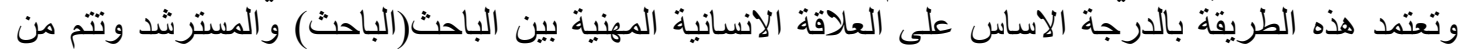
خلالها تبادل المعلومات و اثارة الدافعية للمسترشد في ان يعرض مشكلته التي يعاني منها لكي يتسنى للباحث الني ان 


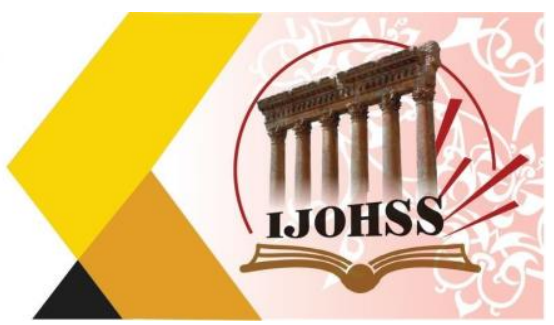

يضع الخطط المناسبة واللازمة لمعالجتها ومساعدة المسترشد على التخلص منها وتتسم هذه الطريقة بالسرية

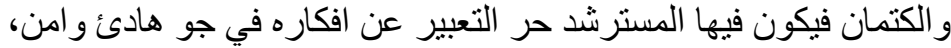

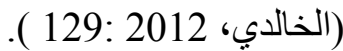

ثانيأ.الارشاد الجماعي : و هو فعالية ارشادية يقوم بها الباحث و الذي يكون متمرس ويقدم الارشاد الى مجمو عة

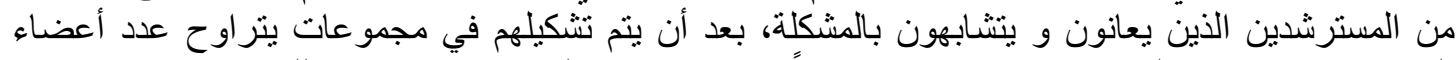

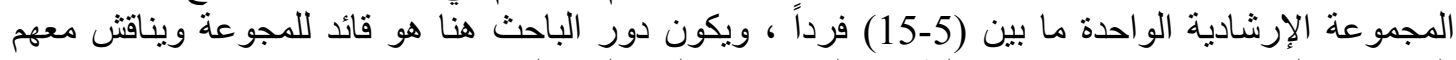

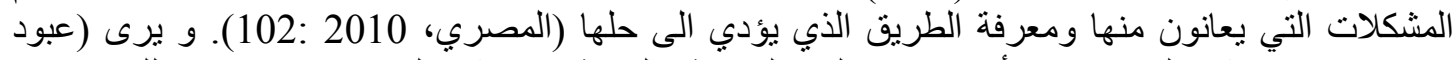

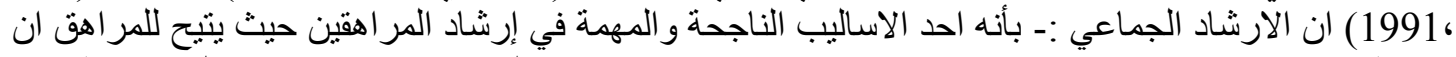

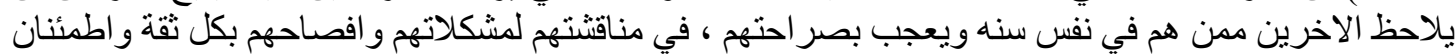

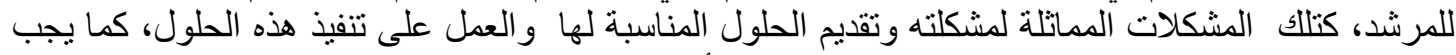

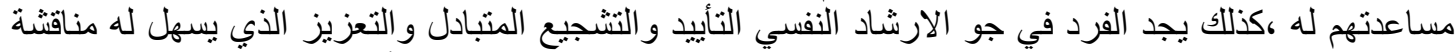

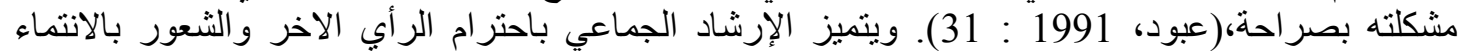

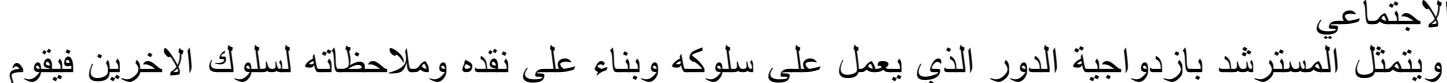

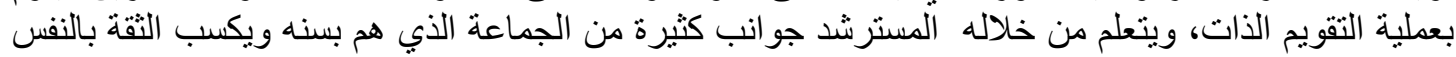

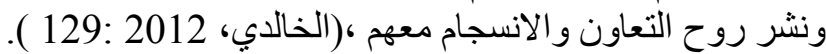

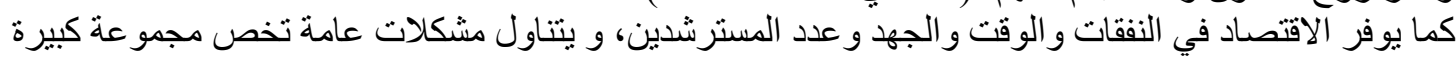

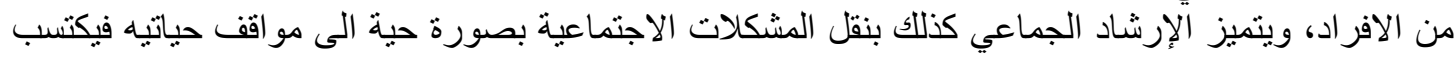

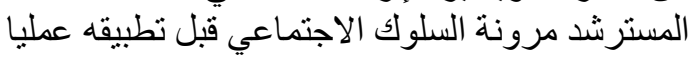

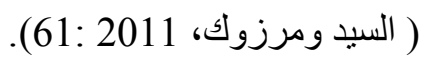

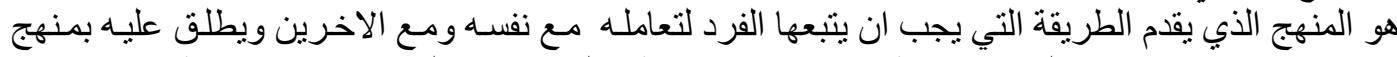

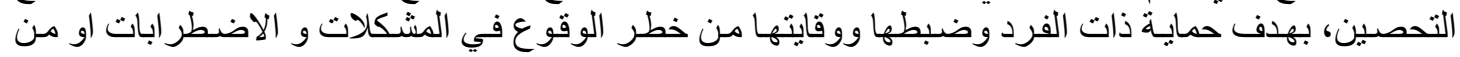

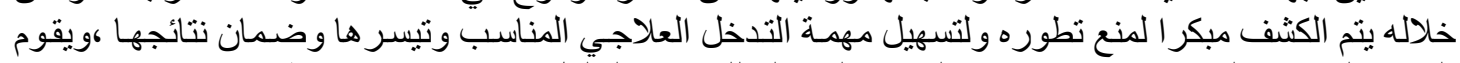

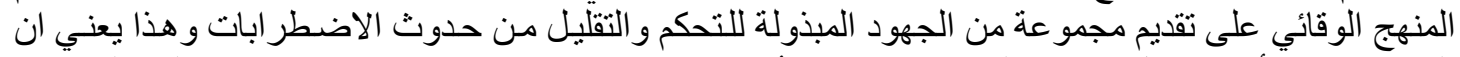

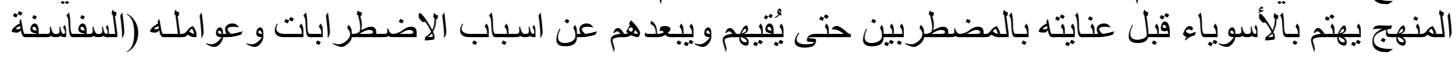
هناك بعض المشكلات التي يصعب التنبؤ بها وتحدث فعلا و هنا يبدا دور المنهج العلاجي في معالجـة المشكلات

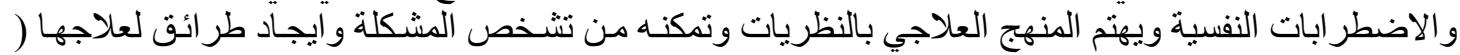
الدفاعي و الخالدي، 2012: 28-29).

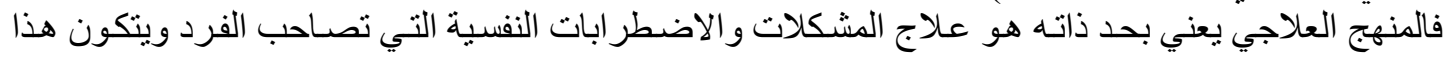

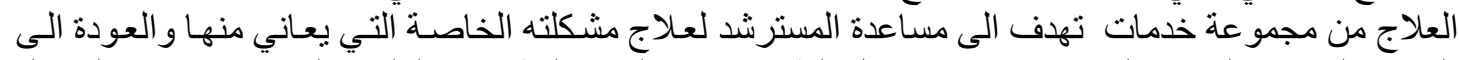

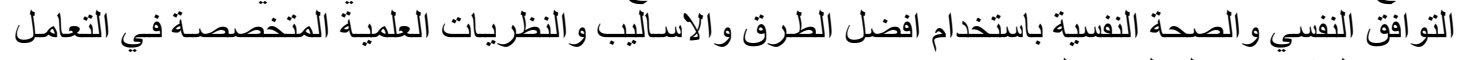

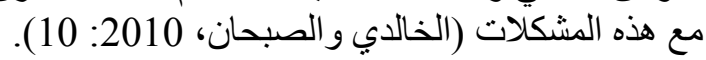
3- المنهج النمائي :

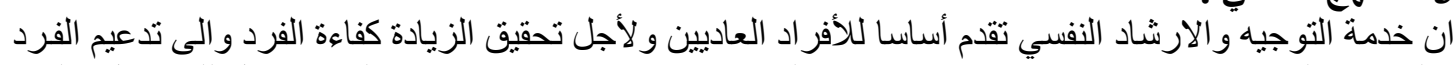

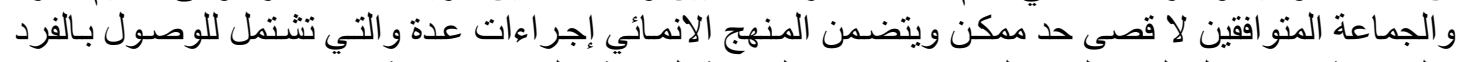

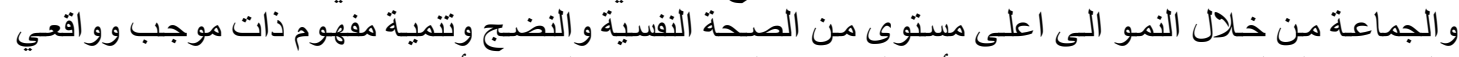

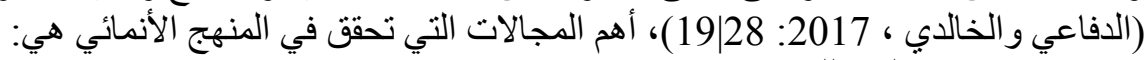
- تحقيق اهداف سليمة للحياة. ـ معرفة الذات وفهمها. 


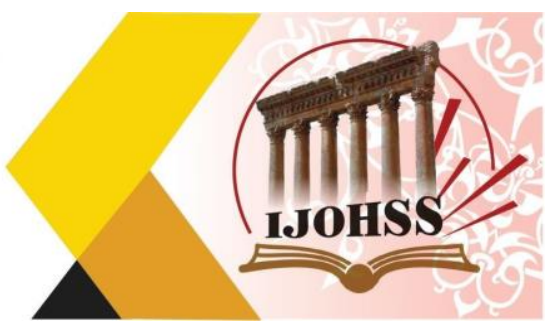

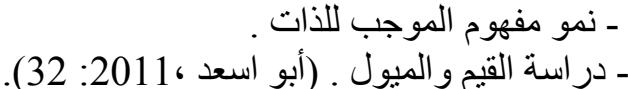

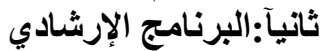

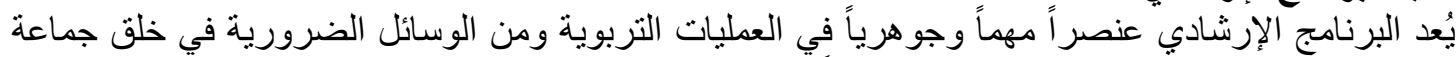

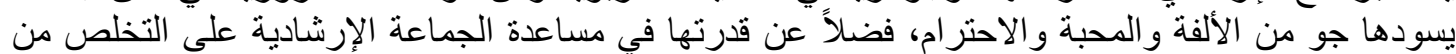
الأزمات ومشاكل جو انب الحياة المختلفة. هو مجموعة من السلوكيات والأنشطة التي تهدف إلى مساعدة المسترشد على مو اجهة مشكلاته و التخلب عليها

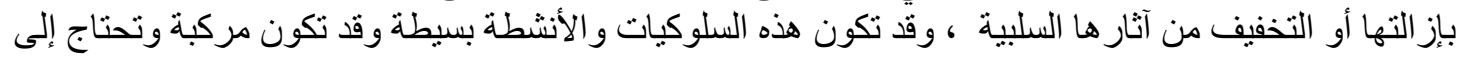

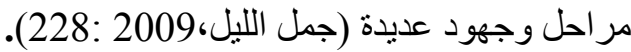
للابرنامج الإرشادي دور كبير في العملية الإرشادية التي تحتوي على خطوات الإدئ عدة تساعد على تقديم الخدمات

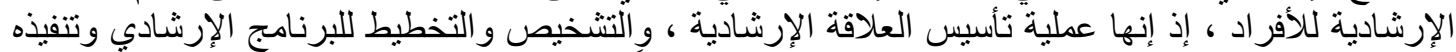

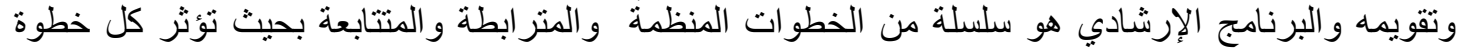

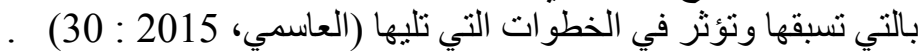

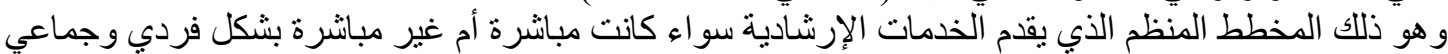

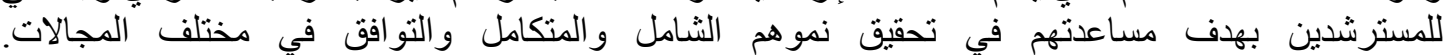

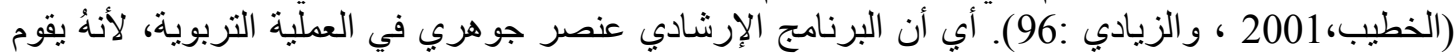

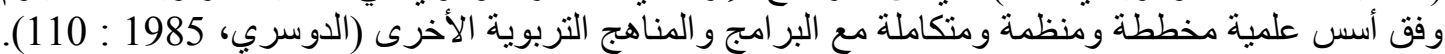

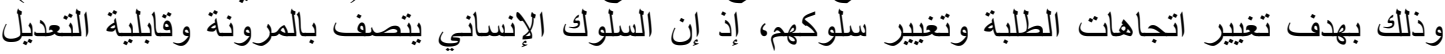

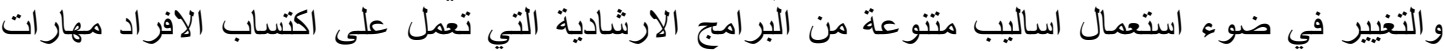

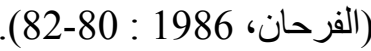

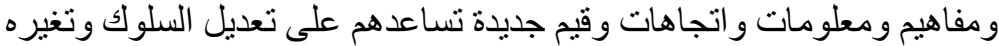

اولا:أهداف البرامج الإرشادية

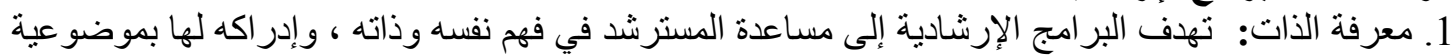

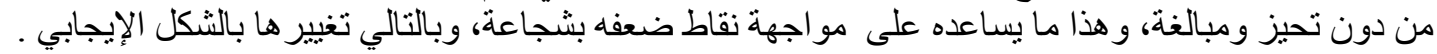

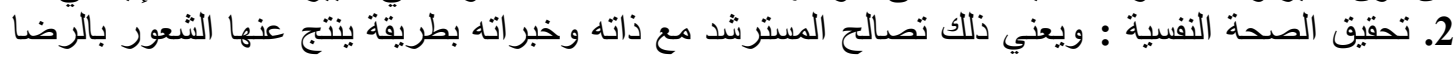

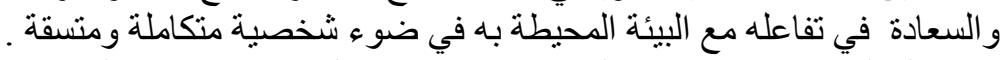

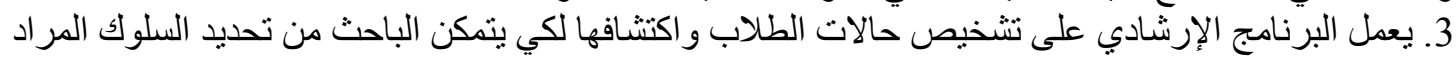

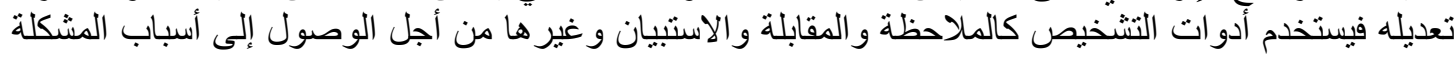
0) التي يعاني منها المسترشد (169)

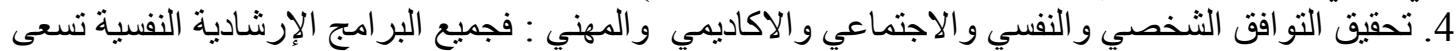

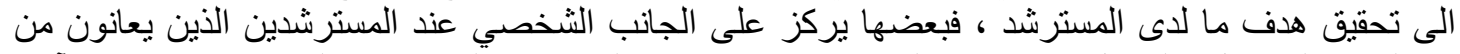

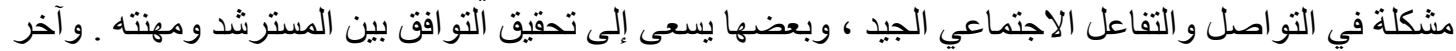

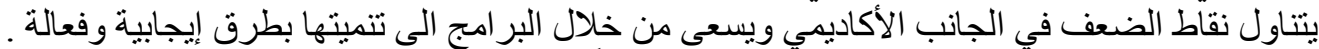

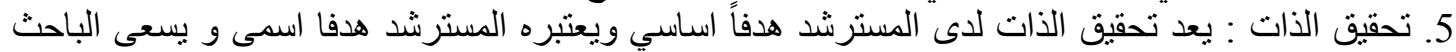

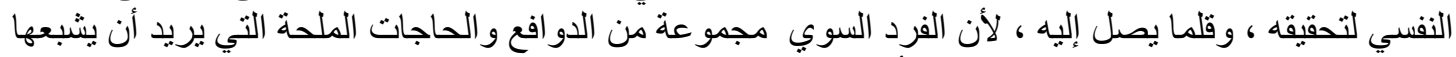

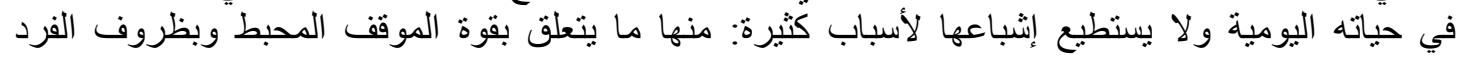

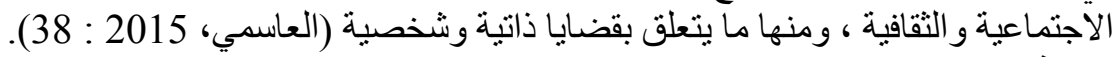

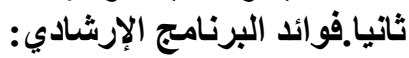

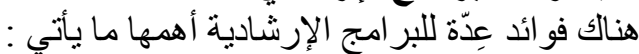

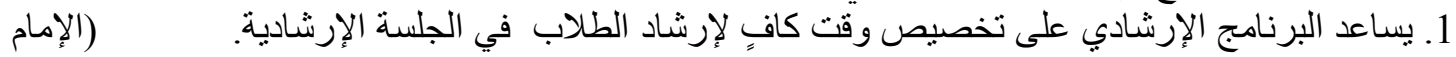
.(16:1999، 


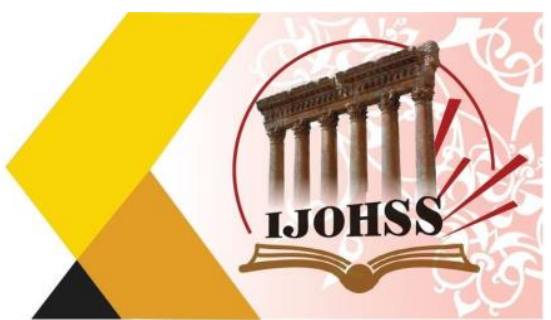

2. يمكّن الطلاب من تلقي الإرشاد بشكل منظم من دون أنَّ بركز على نشاط و احد على حساب الأنشطة المختلفة

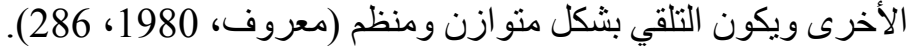

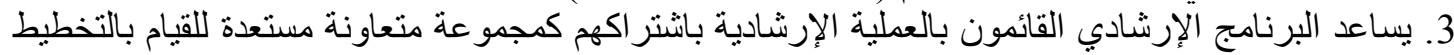

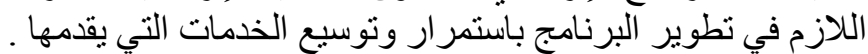

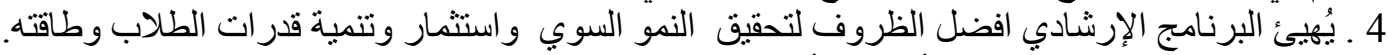

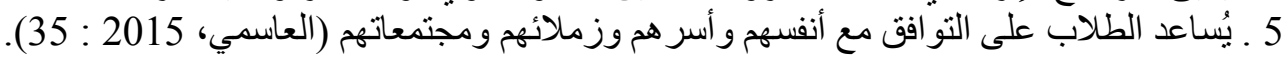

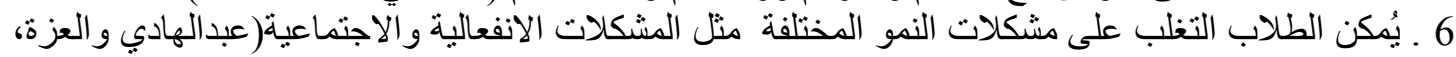

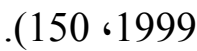

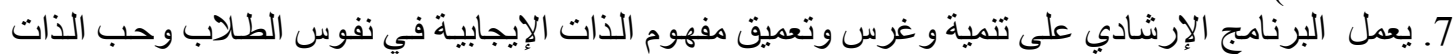

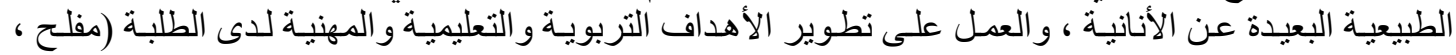
تالثأ.أسس بناء البرنامج الإرشادي:

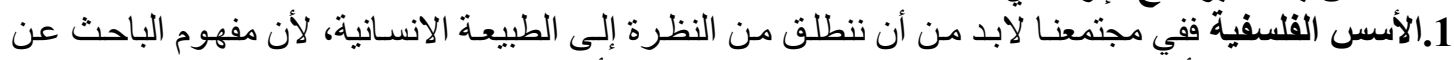

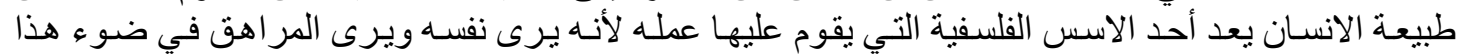

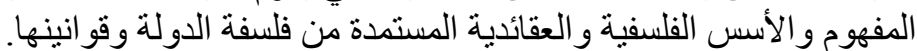

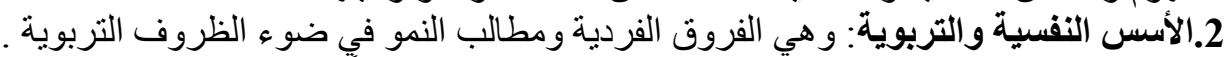

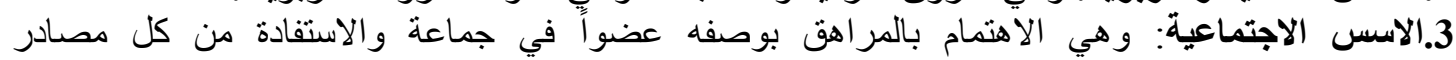

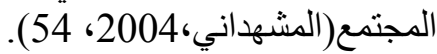

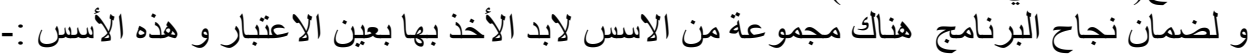

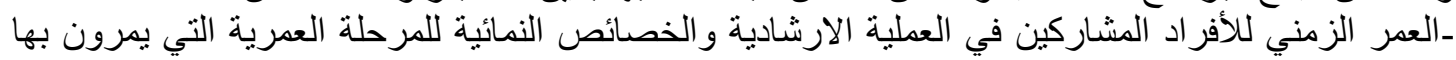

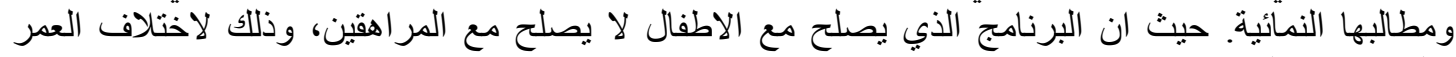
و الخصائص النمائية. مر اعاة الفروق الفردية بين الجنسين وكذلائك الفروق بين نفس الجنس.

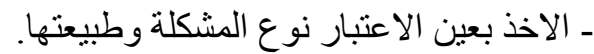

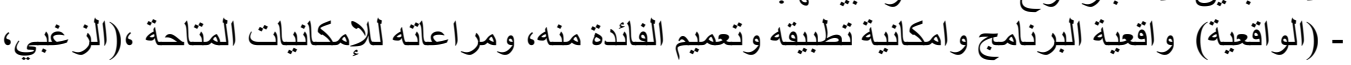

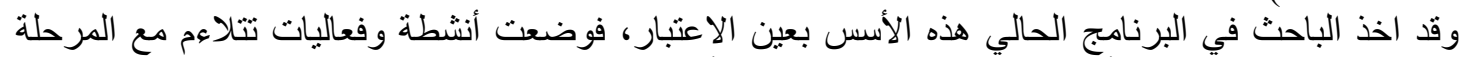

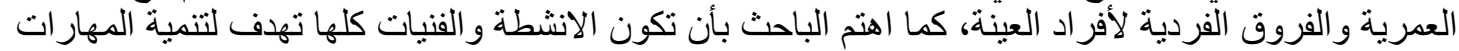
الاجتماعبة الضرورية لإى العينة.

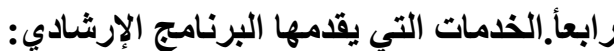

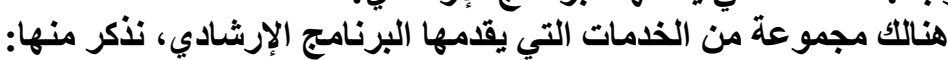

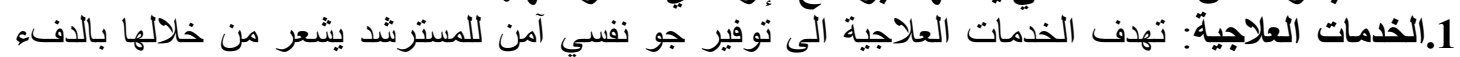

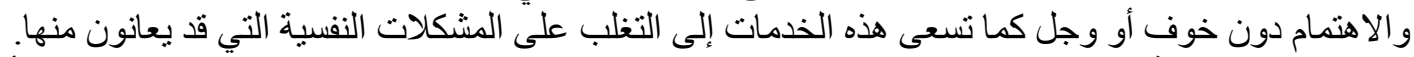

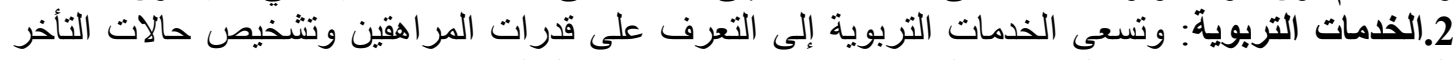

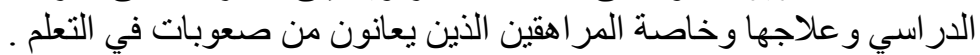

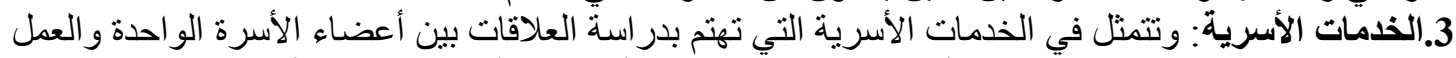

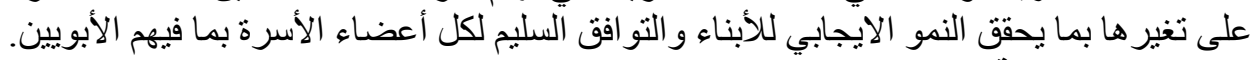

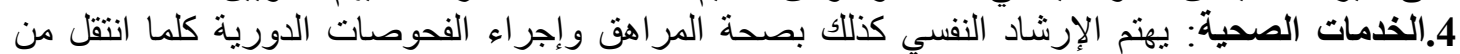
مرحلة نمائية إلى مرحلة نمائية جديدة وتعلم المر اهق العادات الصحية السليمة بتدريبه على أحداث السلوكيات السوية.

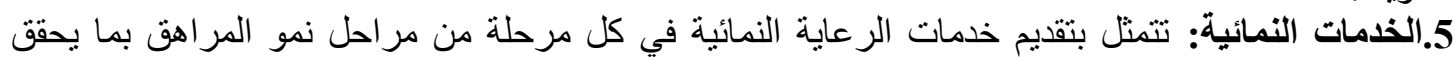
التو افق السليم لله و العمل على تحقيق مطالب النمو في في مختلف التئ التر احل النمائية المتتابعة. 


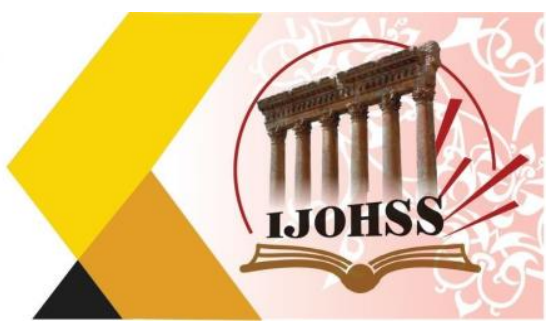

6.الخدمات الاجتماعية: تتضمن الاهتمام بعملية التشئئة الاجتماعبة للفرد وإكسابه الاستجابات السلوكية

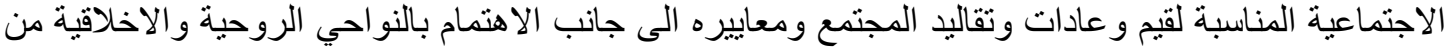

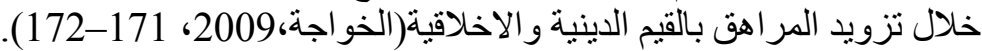

خامسأ. نماذج البرامج الإرشادية

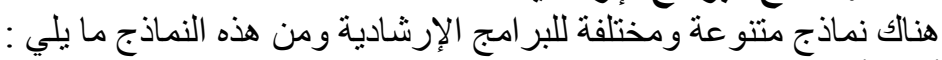

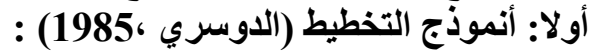

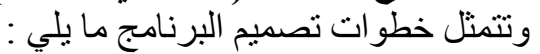

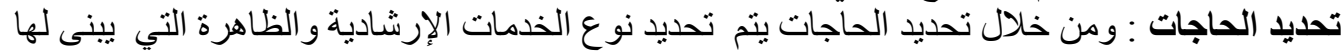

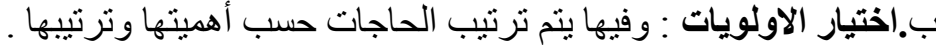

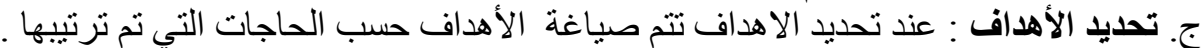

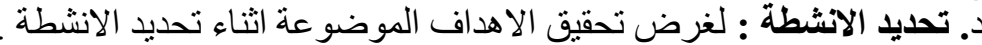

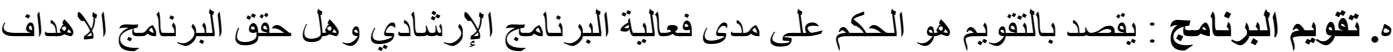

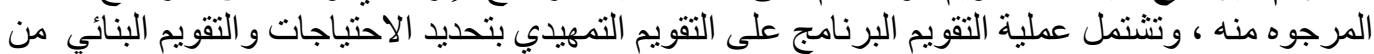

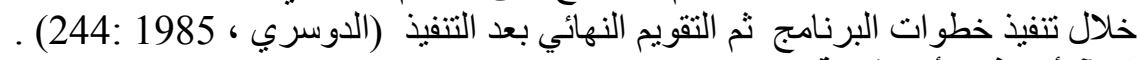

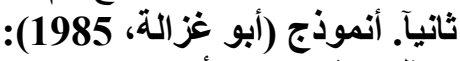

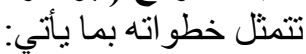

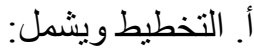
- - تحديد الأهداف التي يرنكز عليها البرنامج الإرشادي.

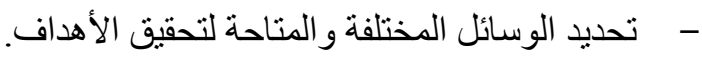

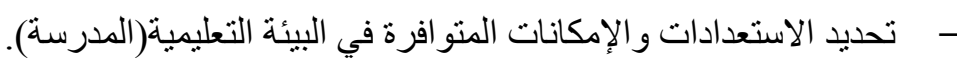

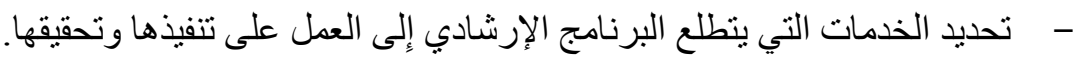

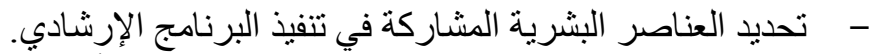

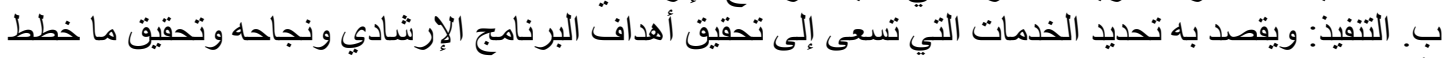

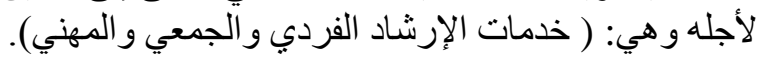

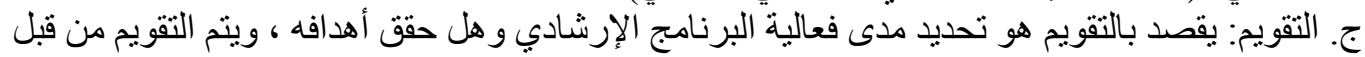
القائمون بالبرنامج الإرشادي بشكل مستمر.

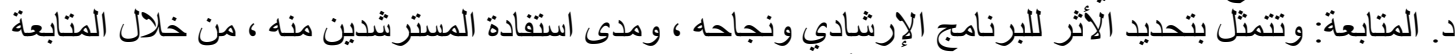

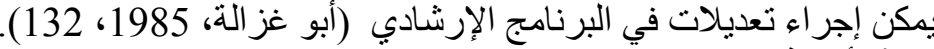

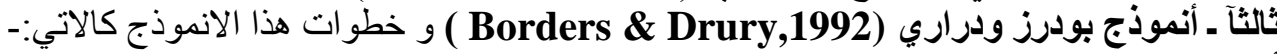

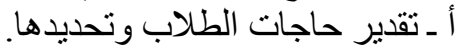
ب ـ ـ صياغة اهداف البرنامج بناء آ على حاجات الطات الطلاب.

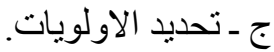

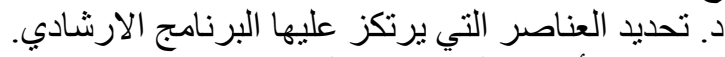

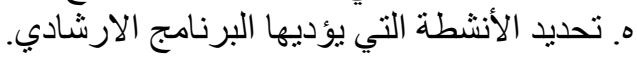

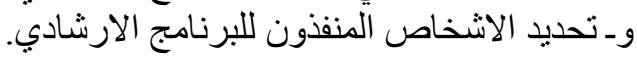

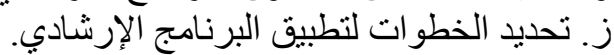

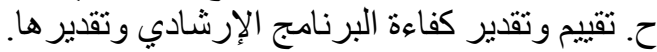

(Borders \& Drury,1992:487- 495) رابعآ: أنموذج( حمد 2013) ويشتمل على الخطو ات التالية:-

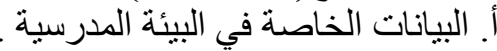

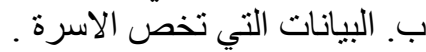


العدد (17) ديسمبر 2020

ISSN: $2415-4822$
Volume (17) December 2020

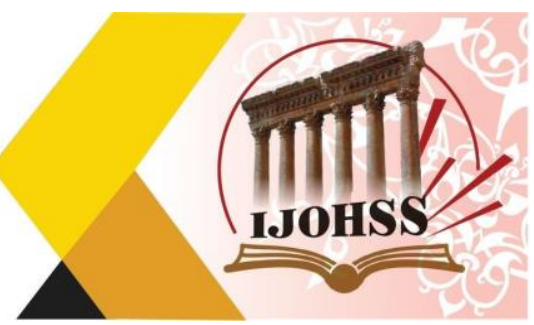

ج. تحديد الحاجات البرنامج الارشادي. د. تحليل البيانات ه. تحديد الاهداف التي يينى عليها البرنامج. و. تقويم الجلسات الارشادية. ز. البيانات الشخصية .

ح. التدريب البيتي ( حمد، 2013: 261). خامسآ: أنموذج التبعلى الامن وتتكون خطوات هذا الأنموذج على الامن الثكل الأتي:

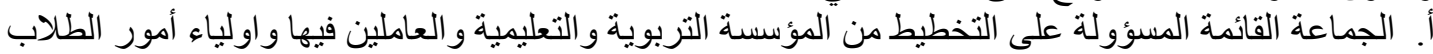
الذين يمثلون المجتمع المحلي و مهمات هذا الانموذج هو فتح قنو ات اتصأ اتصال بين مخططي البرنامج الإرشادي

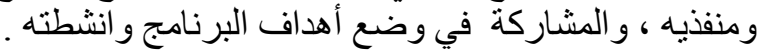

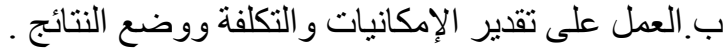

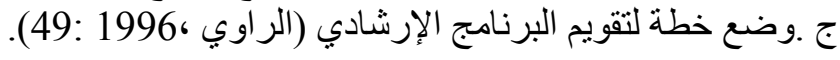

و الافادة العملية من العرض السابق اعتمدت الخصائص العملية المشتركة بين البر امج الارشادية كمعايير مفاضلة

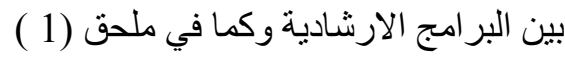

\section{الفصل الثالث: الاجراعات المنهجية}

يتطلب اي بحث علمي اجر اءات محددة منظمة والتي تعتمد على نوع منهجية البحث ، لغرض تحقيق اهداف

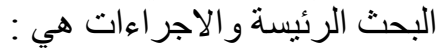
Methodology: تحديد المنهجية اتبعت الباحثة منهجية البحث الوصفي الذي يقوم على وصف البيانات وهي مخرجات عملية القياس وتحليلها

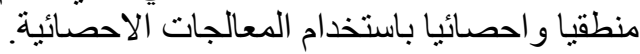

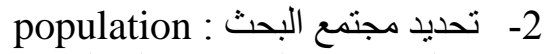

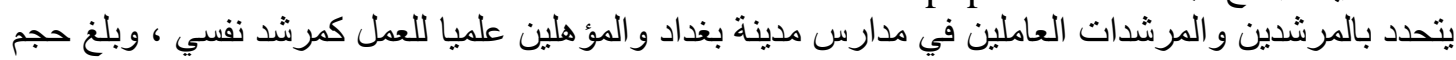

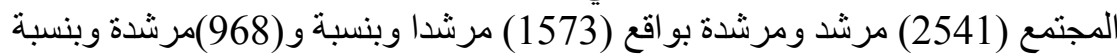

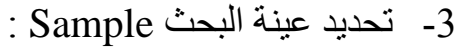
تحدد حجم العينة بعدد نسخ المقاييس المستلمة فقد وزعت 135 نسخة و استردت 135 نس 110 نسخة وبعد تدقيق اجابات افراد العينة تبين هناك 10 مقاييس غير مكتملة الاجابة ، فبقين100 نسخة وهذا العدد يمثل حجم العينة وكما مفصل في جدول ( 1 )

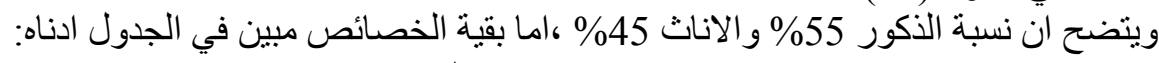

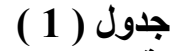

توزيع افزاد العينة حسب المتغيرات النوعية

\begin{tabular}{|c|c|c|c|c|c|c|}
\hline \multirow{2}{*}{ المجموع } & \multicolumn{2}{|c|}{ الخدمة بالســـنـو ات } & \multirow{2}{*}{ المجموع } & \multicolumn{2}{|c|}{ 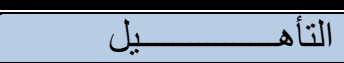 } & \multirow{2}{*}{ الجنس } \\
\hline & سنة اكثرمن & 15-1 سنة & & غير مؤ هل & مؤ هل & \\
\hline 55 & 25 & 30 & 55 & 5 & 50 & الذكور \\
\hline 45 & 27 & 18 & 45 & 2 & 43 & الاناث \\
\hline 100 & 52 & 48 & 100 & 7 & 93 & المجموع \\
\hline
\end{tabular}




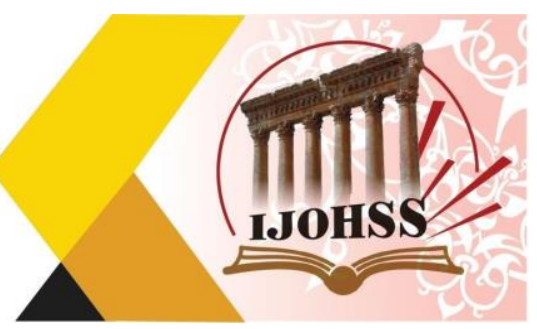

ويقصد غير المؤهل هو معلم يقوم بدور المرشد النفسي، ويبدو هنالك تقارب بين اعداد مستويات المتغيرات النوعية حسب متغير الجنس. 4- اداة البحث: اعدت مقياس المفاضلة واتبعت الخطو اتل الات الاتية:

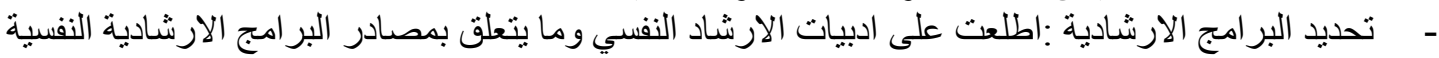

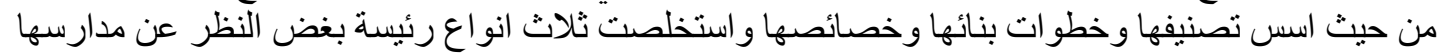

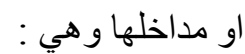

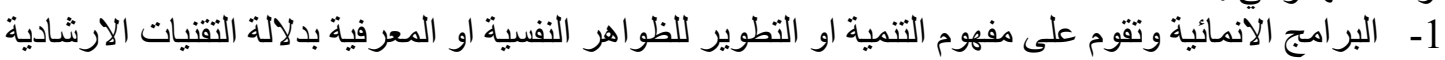

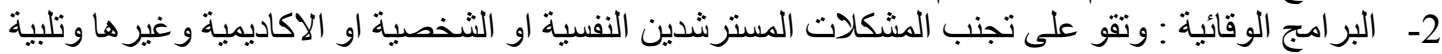

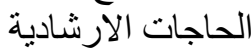
3- البرامج العلاجية :وتقوم على علادة المانية المشكلات الارشادية بأنو اعها المختلفة او تخفيض بعض الاضطر ابات السلوكية وعو امل الصحة النفسية.

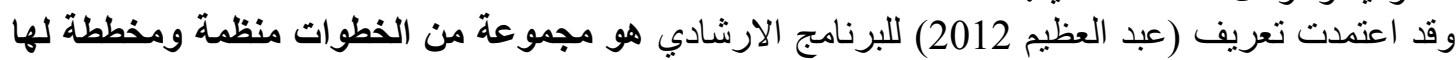

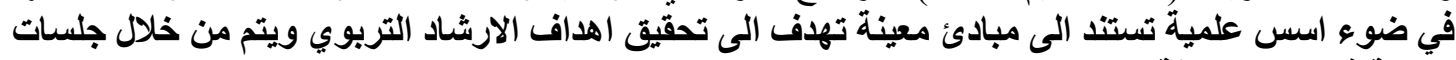

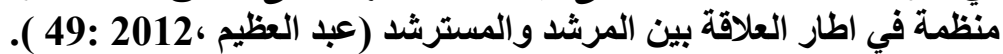

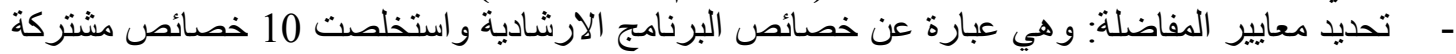

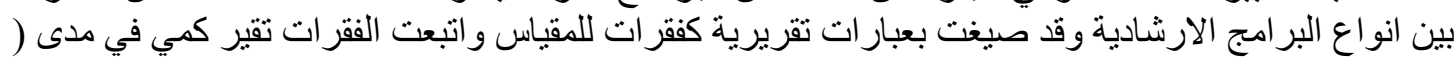
1

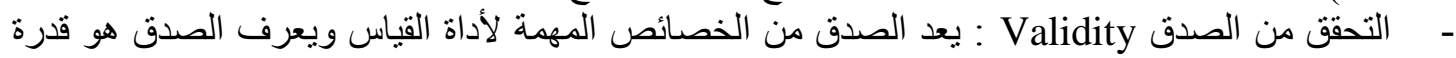

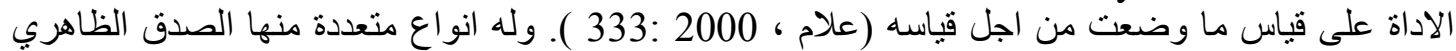
Face Validity

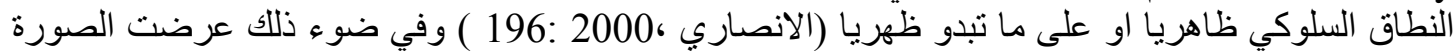

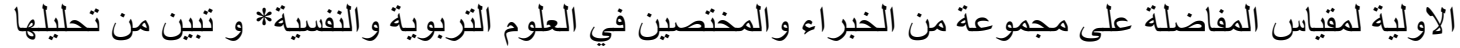

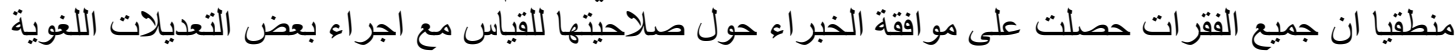
للفقز ات . - م تقدير الثبات Reliability لا يقل الثبات اهية عن الصدق كخاصية جيدة للمقياس ويعرف هو قدرة الاداة

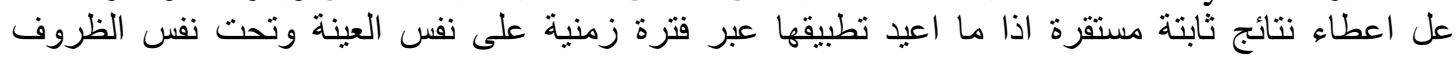

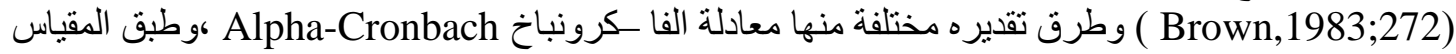

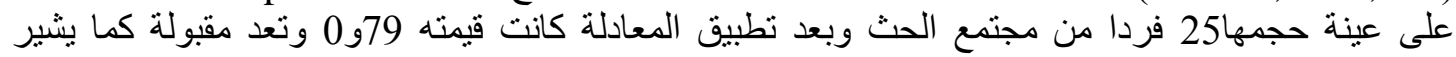

( Foran,1961;384)

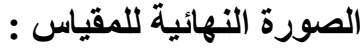

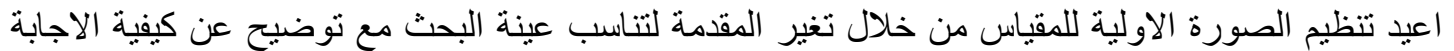

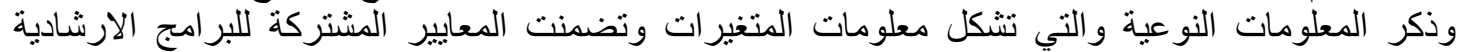

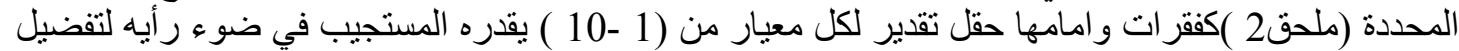

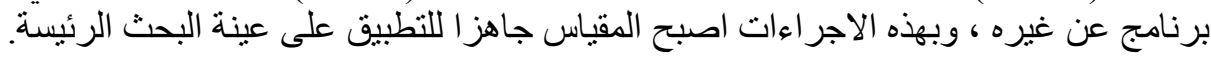

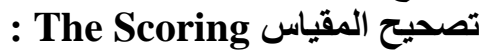
تقوم عملية تصحيح وحساب الدرجة الكلية على الجمع الجبري لدارجات الدات تقدير معايير الدفاضلة لكل برنامج

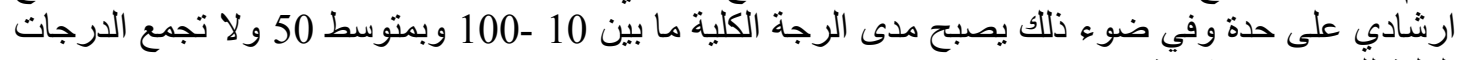

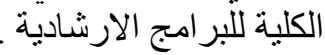

$$
\begin{aligned}
& \text { * الخبر اء:1- أ.د. ناز بدرخان 2-أ.م.د شيماء عبد العزيز عبد الحميد 3-أ. م. .د. أيمان حسن جدعان 4- أ. .م .د، استبرق } \\
& \text { مجيد علي 5- م.م. قصي صباح حسين أدرن }
\end{aligned}
$$




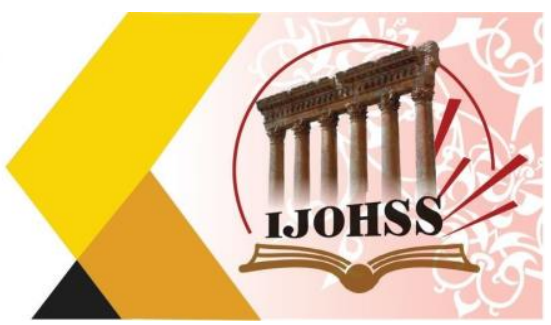

$$
\begin{aligned}
& \text { ولتحديد درجة الافضلية صنفت الى ثلاث مستويات في ضوء الدرجة الدانة الكلية وعلى النحو الاتي: } \\
& \text { افضلية عالية اذا كانت درجة البرنة البامج ما بين } 61 \text { - } 61 \text { - }
\end{aligned}
$$

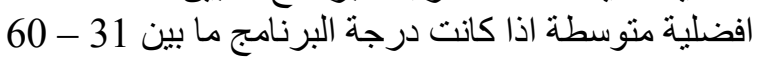

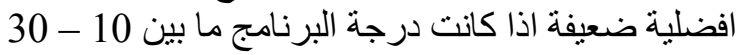

$$
\begin{aligned}
& \text { الوسائل الاحصائية : ستستخدم الوسائل الاتية ماتية }
\end{aligned}
$$

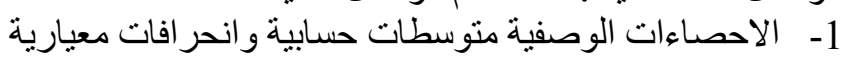

\section{الفصل الرابع: عرض وتففير النتائج}

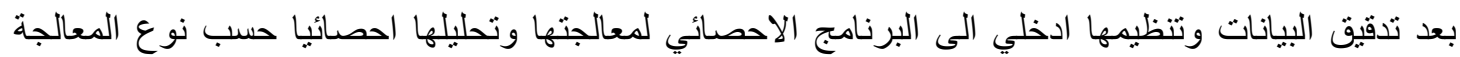

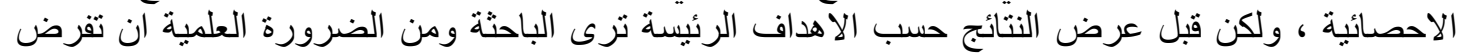

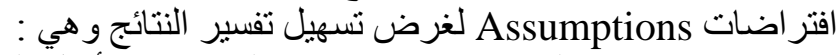

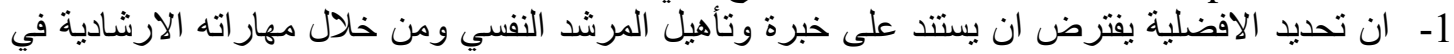

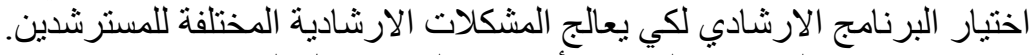

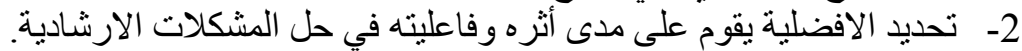

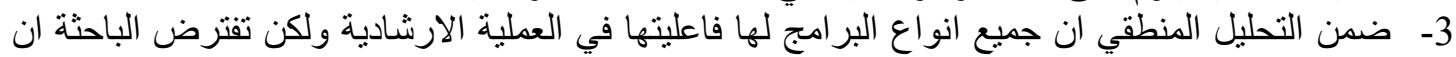

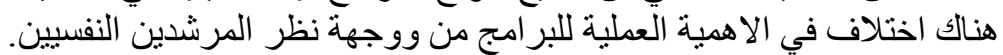

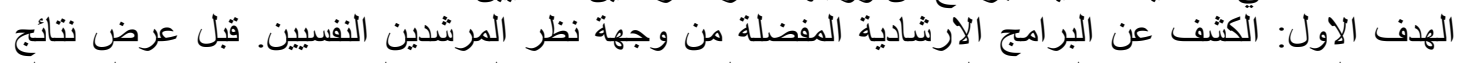

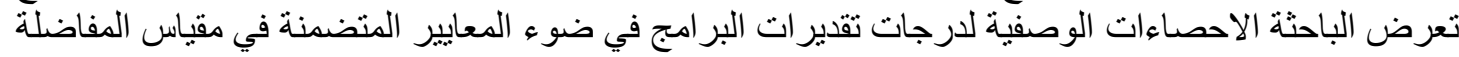

\begin{tabular}{|c|c|c|}
\hline \multicolumn{2}{|r|}{ الاحصاءات الوصفية } & \multirow{2}{*}{ الاربشادي } \\
\hline الانحرياري & المتوسط الحسابي & \\
\hline 7.43 & 63.34 & الانمائي \\
\hline 12.22 & 61.32 & الوقائي \\
\hline 8.22 & 63.46 & العلاجي \\
\hline
\end{tabular}

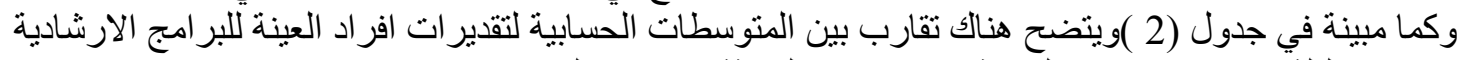

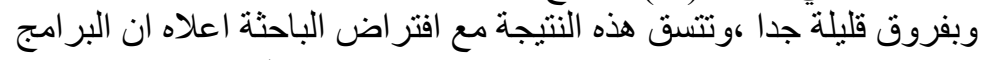

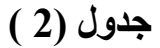

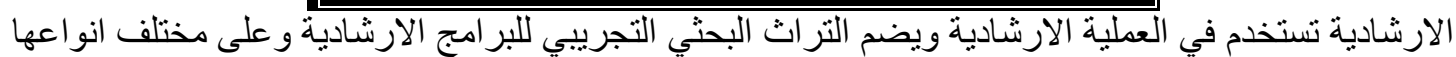

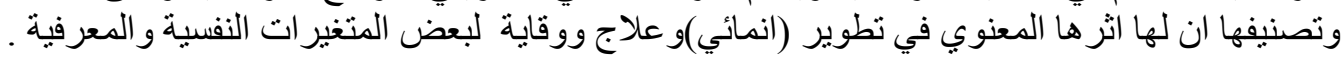

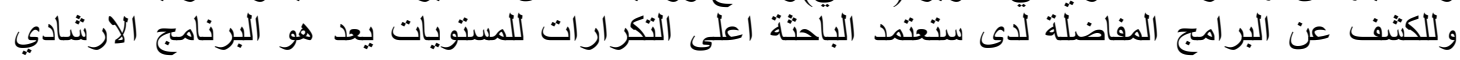

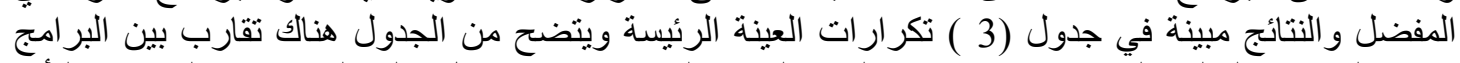

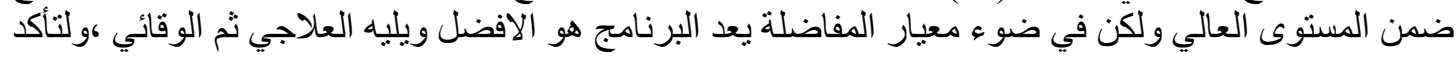

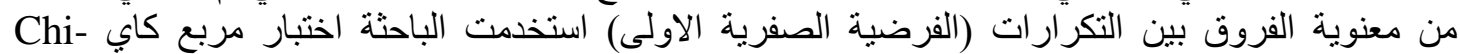
square test

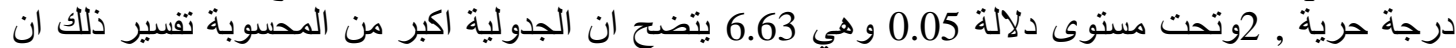
الفرق معنوي و هذه الفروق بين التكرار ات الملاحظة راجعة للصدفة by chance لذا تقبل الفرضية الصفرية . 


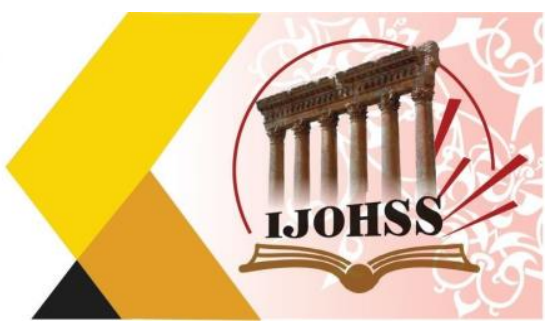

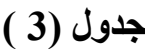

يبين توزيع تكرارات مستويات الافضلية حسب البرامج الارشادية

\begin{tabular}{|c|c|c|c|}
\hline & \multicolumn{2}{|c|}{ البر امج الارشادية } & مستويات \\
\hline العلاجي & الوقائي & الانمائي & المفاضلة \\
\hline 60 & 57 & 62 & العالى \\
\hline 21 & 27 & 27 & المتوسط \\
\hline 19 & 16 & 11 & المنخفض \\
\hline 100 & 100 & 100 & المجموع \\
\hline
\end{tabular}

و لاختبار الفروق بين التكرارات تبعا للمتغيرات النوعية (التأهيل ـالجنس - الخدمة) استخدمت نفس الاختبار

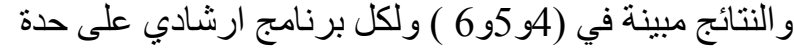

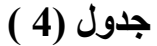

نتائج اختبار الفروق بين التكرارات تبعا لمتغيرات وللثبرنامج الانمائي

\begin{tabular}{|c|c|c|c|c|c|c|}
\hline \multicolumn{6}{|c|}{ المتغبر ات } & \multirow{3}{*}{ الافضلية } \\
\hline \multicolumn{2}{|c|}{ الخدمة } & \multicolumn{2}{|c|}{ التأهيل } & \multicolumn{2}{|c|}{ الجنس } & \\
\hline 15-و اكثر & $15-1$ & غ. مؤ هل & مؤهل & اناث & ذكور & \\
\hline 47 & 57 & 41 & 53 & 40 & 44 & العالي \\
\hline 38 & 35 & 53 & 39 & 54 & 48 & المتوسط \\
\hline 15 & 8 & 6 & 8 & 6 & 8 & المنخفض \\
\hline 100 & 100 & 100 & 100 & 100 & 100 & المجموع \\
\hline \multicolumn{2}{|r|}{3.215} & \multicolumn{2}{|r|}{3.948} & \multicolumn{2}{|r|}{0.89} & كايمة مربع \\
\hline
\end{tabular}

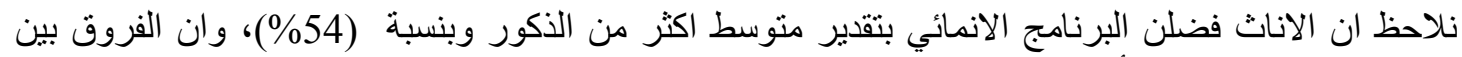

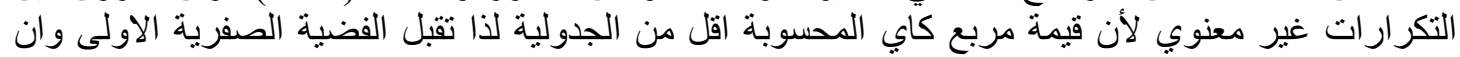

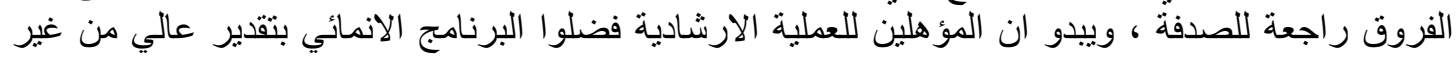

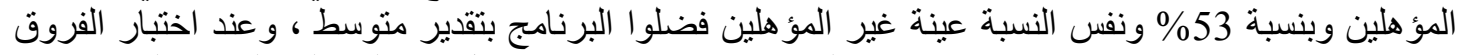

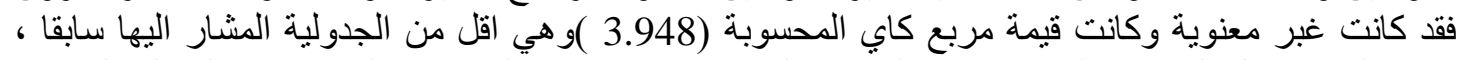

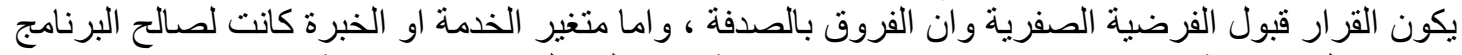

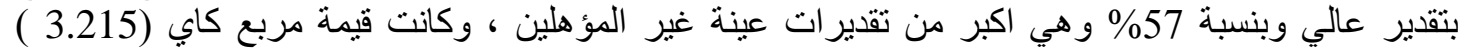

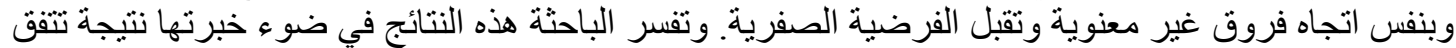
مع اغلب الراسات السابقة والتي خلصت لألهمية البر امج العملية .

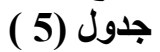

نتائج اختبار الفروق بين التكرارات تبعا لمتغيرات وللبرنامج الوقائي

\begin{tabular}{|c|c|c|c|c|c|c|}
\hline \multicolumn{6}{|c|}{ المتغيرات } & \multirow{3}{*}{ مستويات } \\
\hline \multicolumn{2}{|c|}{ الخدمة } & \multicolumn{2}{|c|}{ التأهيل } & \multicolumn{2}{|c|}{ الجنس } & \\
\hline 15-و اكثر & $15-1$ & غ. مؤهل & مؤ هل & اناث & ذكور & \\
\hline 39 & 53 & 43 & 55 & 38 & 43 & العالي \\
\hline 44 & 40 & 50 & 38 & 47 & 51 & المتوسط \\
\hline 7 & 7 & 7 & 7 & 15 & 6 & المنخفض \\
\hline 100 & 100 & 100 & 100 & 100 & 100 & المجموع \\
\hline
\end{tabular}



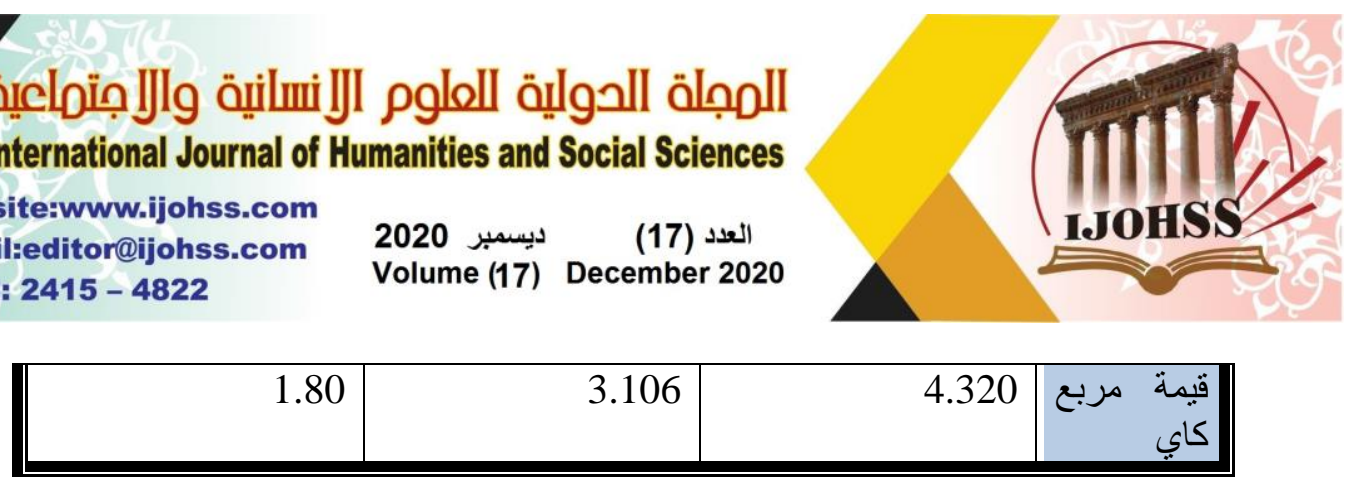

يتضح من بيانات جدول ( 5 ) لا نختلف افضلية البرنامج الوقائي هن البرنامج الانمائي من حيث متغير الجنس الإنس

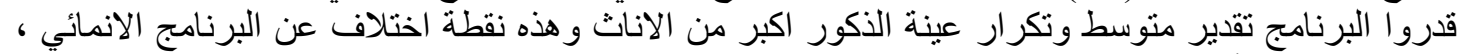

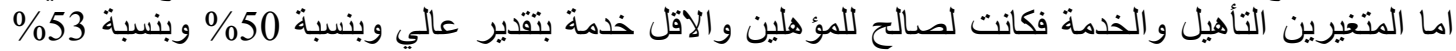

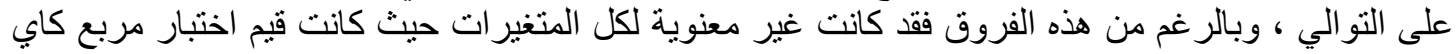

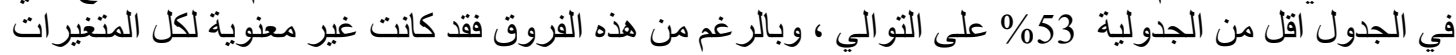

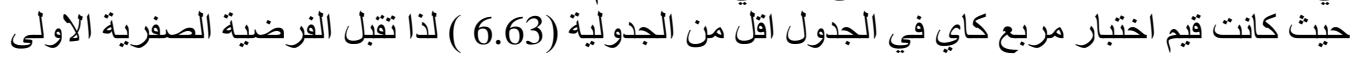

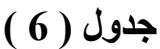

نتائج اختبار الفروق بين التكرارات تبعا لمتفيرات وللبرنامج العلاجي

\begin{tabular}{|c|c|c|c|c|c|c|}
\hline \multicolumn{6}{|c|}{ المتغير ات } & \multirow{3}{*}{ الافضلية } \\
\hline \multicolumn{2}{|r|}{ الخدمة } & \multicolumn{2}{|c|}{ التأهيل } & \multicolumn{2}{|r|}{ الجنس } & \\
\hline 15-و اكثر & $15-1$ & غ. مؤهل & مؤ هل & اناث & ذكور & \\
\hline 40 & 35 & 37 & 57 & 47 & 51 & العالي \\
\hline 50 & 45 & 38 & 36 & 43 & 40 & المتوسط \\
\hline 10 & 20 & 25 & 7 & 10 & 9 & المنخفض \\
\hline \multirow{2}{*}{\multicolumn{2}{|c|}{$\frac{100}{0.275}$}} & 100 & 100 & 100 & 100 & المجموع \\
\hline & & & 16.31 & & 0.321 & كايمة ربع \\
\hline
\end{tabular}

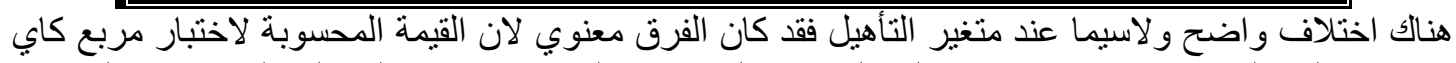

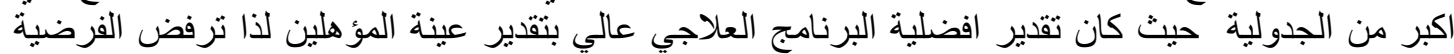

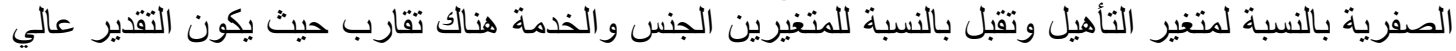

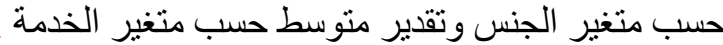

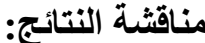

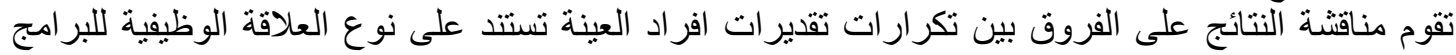

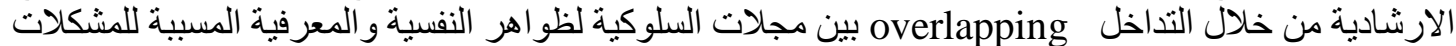
الارشادية بمختلف انواعها فضلا عن الحاجات الارشادية للمسترشدين ، ويمكن القول ان العلاقية العادية تكاملية في

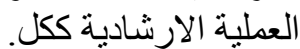

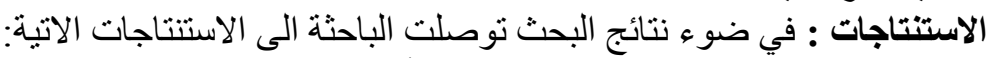

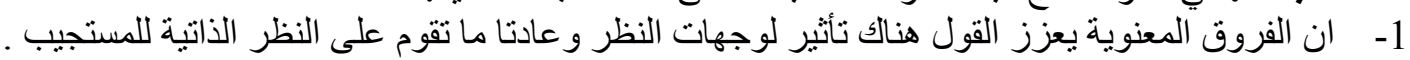

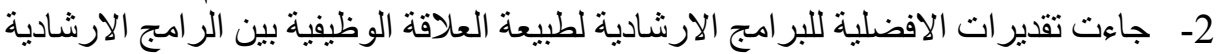

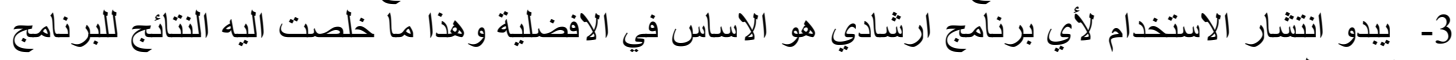
الارشادي العلاجي الإني 4- يبدو هناك امكانية لاعتماد ترتيب البر امج كدليل لاختيار البرنامج المناسب.

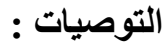

1- ت تمية الوعي بالبر امج الارشادية لدى المرشدين النفسيين من خلال دور ات تعليمية لهم خلال الخدمة

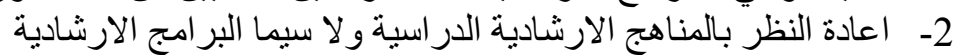

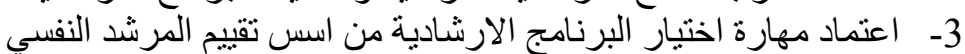

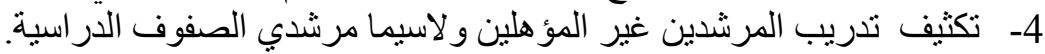

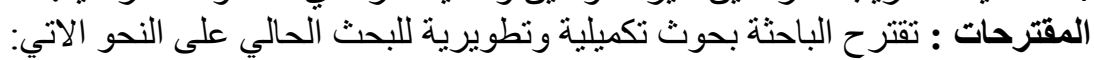

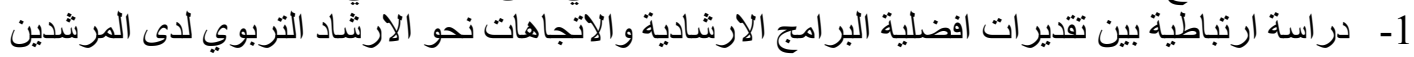




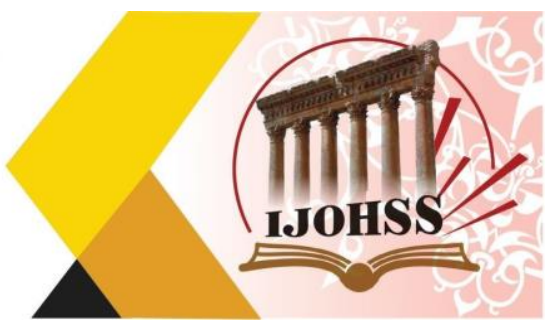

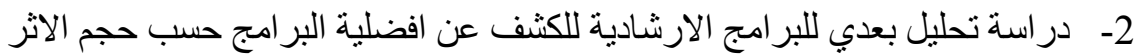
3- قياس دور كل من المدير والمشرف الاختصاصي في تقدير افضلية البرامج المجائ

المصادر والمراجع

1. ابو اسعد ، (2009)، المهار ات الإرشادية، دار المسيرة للنشر و التوزيع، عمان، الأردن.

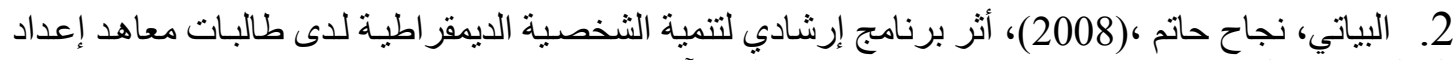
المعلمات،رسالة ماجستير غير منشورة، جامعة بغداد، المكلية الآداب. 3. الخالدي ،أمل إبر اهيم (2012 ):أساسيات الإرشـاد و الصـحة النفسية ،دار الكتب و الوثنائق العر اقيـة لسـنة .2012 4. الخالدي ، عطا الله فؤ اد و الصبحان، ابر اهيم سالم (2010) : نماذج في التطبيق العلمي للإرشـاد في المدارس

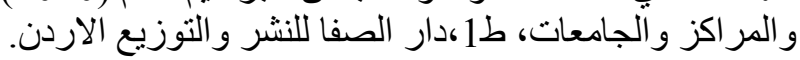

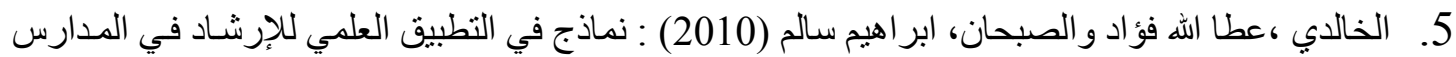
و المر اكز و الجامعات، ط1،دار الصفا للنشر و التوزيع الاردن.

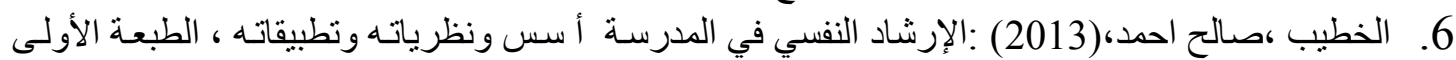

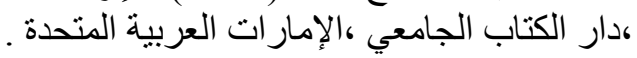

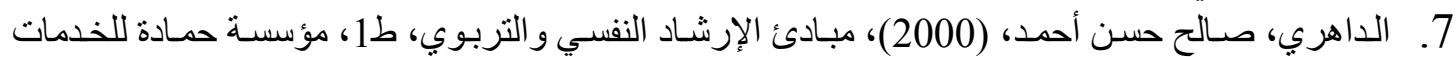
و الدراسات البحثية ودار الكندي للنشر ، الأردن.

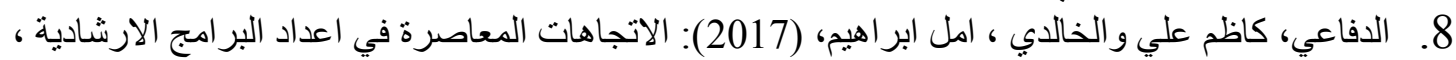
ط1، مكتبة أليمامة للطباعة والنشي والنشر. 9. الدوسري ، صـالح جاسم (1985):الاتجاهـات العلميـة في تخطيط بر امج التوجيه و الارشـاد ،مجلة رسـالة

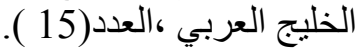

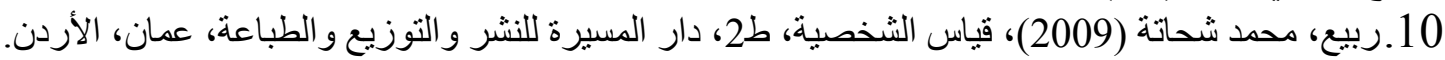

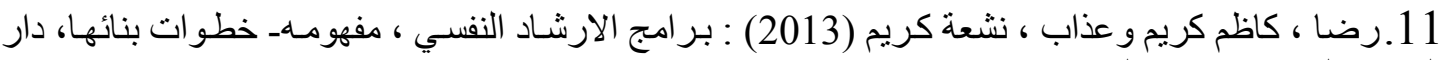
الكتب و الوثائق، بغداد- العر اق.

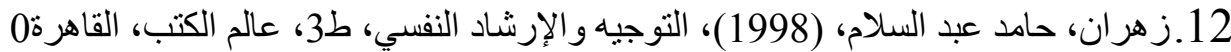

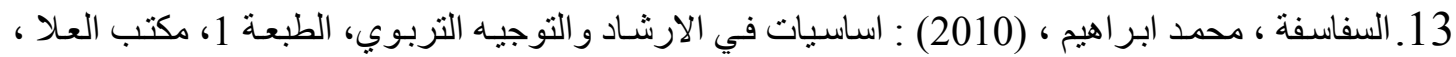
للنشر و التوزيع، الكويت.

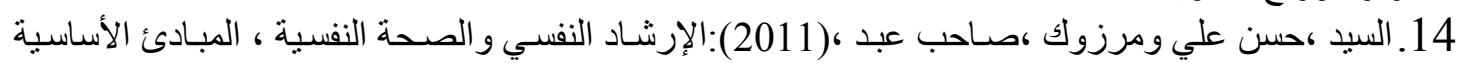

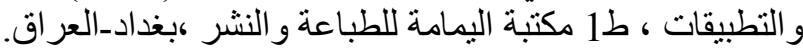

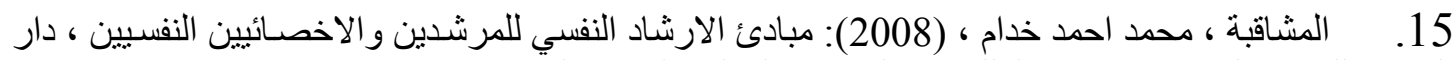

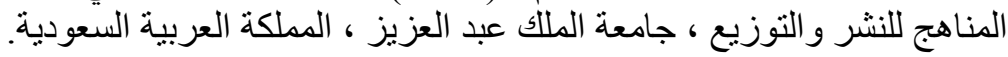

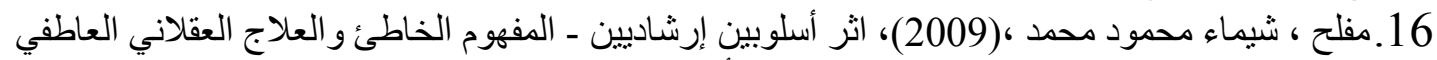

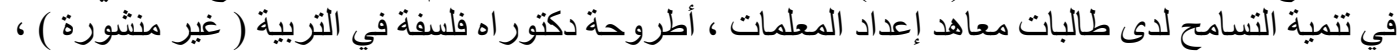
كلية التربية ، الجامعة المستنصرية التيات

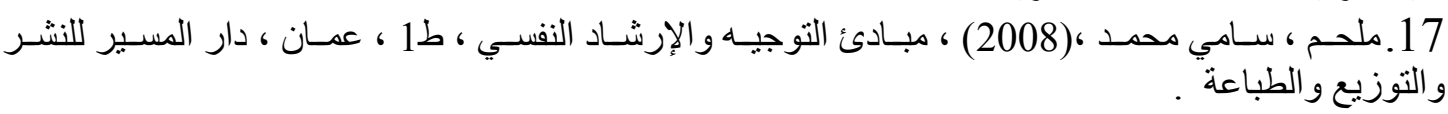
18. Arkoff, A. (1968), Adjustment of Mental Health, McGraw-Hill Book Company, New York. 


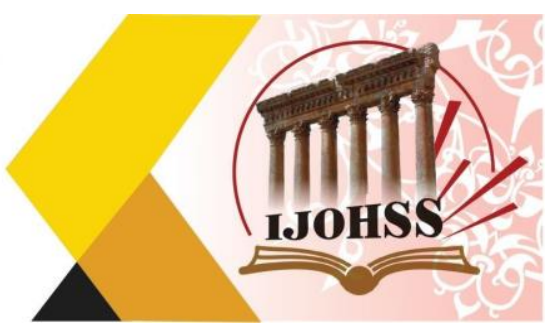

19.Borders, L.D, \& Drury, Sandra, M.D, (1992), Comprehensive school counseling programs, are view for policymakers and practitioners journal of counseling and development volume(70).

20.Cobb, Nancy. J. (2001), Adolescence Continuity, Change , and Diversity, (4 ${ }^{\text {th }}$ ed.). Mayfield publishing Company, California.

21.Corey,( 1990), Gerald, theory and practice of group an selling, $3^{\text {rd }}$-ed, Brooks cde pub co. Pacific Grove California.

22.Ebel, Robert. L. (1972), Essentials of Educational Measurement, Prentice - Hall, Inc, New Jersey.

23.Elisser, K. R. (1985), Notes on Problems of teaching use in the suchonalytic Treatment of adolescent_Psychoanalytic tic Study of the Child, D.B.

24.Ellis , A. ,\& Bernard, M. (1999), What is Rational Emotive Therapies , New York

25.Feldman, R and saletsky, R.D,(1989), Teacher locus of control and susceptibility .to Expectancy, information about self and student, psychological Abstract.

26. Feldman, Robert. S. (2003), Development Across the Life Span, (3 ${ }^{\text {rd }}$ ed). Pearson Education, Inc, Upper Saddle River, New Jersey.

27. Glasser ,william ,2000, The new reality therapy ,the william Glasser Institute chats worth U.S.A.(http://www.w Glasserinst.com/the new.htm) .

28. Glasser, william ,1965, Reality therapy New York Harper and Row . U.S.A. . (http://www.wglasser com/research.htm).

29. Glasser, william ,1989, what is choice therory ,the william glasser Institute ,chats worth .U.S.A. (http://www.wglasser com/research.htm).

30.Hart ,Elizabeth ,A. (1992), Using Reality therapy for exrcise Initiat ,Journal of Reality ,therapy .

31.Higgins, R.E,(1983), Development and management of counseling programs and guidance servies Macmillan company.

32. Hoffman, J.A. (1984): psychological Iseparation of late adolescents. From

33.Hollingdale, R.J, (1987), Twilight of the idols and the antichrish, New York, Penguin Books.

34.Holland, Morris. K. (1981), Introductory Psychology, D.C. Heath and Company. U.S.A. 